University of Nebraska - Lincoln

DigitalCommons@University of Nebraska - Lincoln

U.S. Department of Veterans Affairs Staff

Publications

U.S. Department of Veterans Affairs

$9-2008$

\title{
SHEA/APIC Guideline: Infection prevention and control in the long- term care facility
}

Philip W. Smith

University of Nebraska Medical Center, pwsmith@unmc.edu

Gail Bennett

ICP Associates, Inc, gailbennett@icpassociates.com

Suzanne Bradley

University of Michigan Medical School, sbradley@umich.edu

Paul Drinka

University of Wisconsin-Madison

Ebbing Lautenbach

Hospital of the University of Pennsylvania, ebbing@mail.med.upenn.edu

See next page for additional authors

Follow this and additional works at: https://digitalcommons.unl.edu/veterans

Smith, Philip W.; Bennett, Gail; Bradley, Suzanne; Drinka, Paul; Lautenbach, Ebbing; Marx, James; Mody, Lona; Nicolle, Lindsay; and Stevenson, Kurt, "SHEA/APIC Guideline: Infection prevention and control in the long-term care facility" (2008). U.S. Department of Veterans Affairs Staff Publications. 75.

https://digitalcommons.unl.edu/veterans/75

This Article is brought to you for free and open access by the U.S. Department of Veterans Affairs at DigitalCommons@University of Nebraska - Lincoln. It has been accepted for inclusion in U.S. Department of Veterans Affairs Staff Publications by an authorized administrator of DigitalCommons@University of Nebraska - Lincoln. 


\section{Authors}

Philip W. Smith, Gail Bennett, Suzanne Bradley, Paul Drinka, Ebbing Lautenbach, James Marx, Lona Mody, Lindsay Nicolle, and Kurt Stevenson 


\section{special communication}

\section{SHEA/APIC Guideline: Infection prevention and control in the long-term care facility}

Philip W. Smith, MD, ${ }^{\mathrm{a}}$ Gail Bennett, RN, MSN, CIC, ${ }^{\mathrm{b}}$ Suzanne Bradley, MD, ${ }^{\mathrm{c}}$ Paul Drinka, MD, ${ }^{\mathrm{d}}$ Ebbing Lautenbach, MD, ${ }^{\mathrm{e}}$ James Marx, RN, MS, CIC, ${ }^{\mathrm{f}}$ Lona Mody, MD, ${ }^{\mathrm{g}}$ Lindsay Nicolle, MD, ${ }^{\mathrm{h}}$ and Kurt Stevenson, $\mathrm{MD}^{\mathrm{i}}$ July 2008

Long-term care facilities (LTCFs) may be defined as institutions that provide health care to people who are unable to manage independently in the community. ${ }^{1}$ This care may be chronic care management or short-term rehabilitative services. The term nursing home is defined as a facility licensed with an organized professional staff and inpatient beds that provides continuous nursing and other services to patients who are not in the acute phase of an illness. There is considerable overlap between the 2 terms.

More than 1.5 million residents reside in United States (US) nursing homes. In recent years, the acuity

Professor of Infectious Diseases, Colleges of Medicine and Public Health, University of Nebraska Medical Center, Omaha, Nebraska; President, ICP Associates, Inc, Rome, Georgia ${ }^{\text {b }}$ Professor of Internal Medicine, Divisions of Infectious Diseases and Geriatric Medicine VA Ann Arbor Healthcare System, and the University of Michigan Medical School, Ann Arbor, Michigan ${ }^{c}$; Clinical Professor, Internal Medicine/Geriatrics, University of Wisconsin-Madison, and Medical College of Wisconsin-Milwaukee, Wisconsin ${ }^{\mathrm{d}}$; Associate Professor of Medicine and Epidemiology, Associate Hospital Epidemiologist, Hospital of the University of Pennsylvania, and Senior Scholar, Center for Clinical Epidemiology and Biostatistics, University of Pennsylvania School of Medicine, Philadelphia, Pennsylvania ${ }^{\text {; }}$ Infection Preventionist, Broad Street Solutions, San Diego, California'; Assistant Professor, Divisions of Geriatric Medicine, University of Michigan Medical School, and Geriatric Research and Education Center, Veteran Affairs Ann Arbor Healthcare System, Ann Arbor, Michigan̋̊; Professor, Internal Medicine and Medical Microbiology, University of Manitoba, Winnipeg, Manitoba, Canada ${ }^{\text {h }}$; and Associate Professor of Medicine, Division of Infectious Diseases, Department of Internal Medicine, The Ohio State University College of Medicine, Columbus, Ohio.'

Address correspondence to Philip W. Smith, MD, Section of Infectious Disease, University of Nebraska Medical Center, 985400 Nebraska Medical Center, Omaha, NE 68198-5400 E-mail: pwsmith@unmc.edu.

Am J Infect Control 2008;36:504-35.

0196-6553/ $\$ 34.00$

Copyright (c) 2008 by the Association for Professionals in Infection Control and Epidemiology, Inc, and Society for Healthcare Epidemiology.

doi:10.1016/j.ajic.2008.06.00। of illness of nursing home residents has increased. LTCF residents have a risk of developing health careassociated infection (HAI) that approaches that seen in acute care hospital patients. A great deal of information has been published concerning infections in the LTCF, and infection control programs are nearly universal in that setting. This position paper reviews the literature on infections and infection control programs in the LTCF.

Recommendations are developed for long-term care (LTC) infection control programs based on interpretation of currently available evidence. The recommendations cover the structure and function of the infection control program, including surveillance, isolation precautions, outbreak control, resident care, and employee health. Infection control resources are also presented.

Hospital infection control programs are well established in the US. Virtually every hospital has an infection control professional (ICP), and many larger hospitals have a consulting hospital epidemiologist. The Study on the Efficacy of Nosocomial Infection Control (SENIC) documented the effectiveness of a hospital infection control program that applies standard surveillance and control measures. ${ }^{2}$

The major elements leading to a HAI are the infectious agent, a susceptible host, and a means of transmission. These elements are present in LTCFs as well as in hospitals. It is not surprising, therefore, that almost as many HAIs occur annually in LTCFs as in hospitals in the US. ${ }^{3}$

The last 2 decades have seen increased recognition of the problem of infections in LTCFs, with subsequent widespread development of LTCF infection control programs and definition of the role of the ICP in LTCFs. An increasingly robust literature is devoted to LTC infection control issues such as the descriptive epidemiology of LTCF infections, the microbiology of LTCF infections, outbreaks, control measures, and isolation. Nevertheless, there is as yet no SENIC-equivalent study 
documenting the efficacy of infection control in LTCFs, and few controlled studies have analyzed the efficacy or cost-effectiveness of the specific control measures in that setting.

Although hospitals and LTCFs both have closed populations of patients requiring nursing care, they are quite different. They differ with regard to payment systems, patient acuity, availability of laboratory and $\mathrm{x}$-ray, and nurse-to-patient ratios. More fundamentally, the focus is different. The acute care facility focus is on providing intensive care to a patient who is generally expected to recover or improve, and high technology is integral to the process. In LTCFs, the patient population may be very heterogeneous. Most LTCFs carry out plans of care that have already been established in acute care or evaluate chronic conditions. The LTCF is functionally the home for the resident, who is usually elderly and in declining health and will often stay for years, hence comfort, dignity, and rights are paramount. It is a low-technology setting. Residents are often transferred between the acute care and the LTC setting, adding an additional dynamic to transmission and acquisition of HAIs.

Application of hospital infection control guidelines to the LTCF is often unrealistic in view of the differences noted above and the different infection control resources. Standards and guidelines specific to the LTCF setting are now commonly found. The problem of developing guidelines applicable to all LTCFs is compounded by the varying levels of nursing intensity (eg, skilled nursing facility vs assisted living), LTCF size, and access to physician input and diagnostic testing.

This position paper provides basic infection control recommendations that could be widely applied to LTCFs with the expectation of minimizing HAIs in LTC. The efficacy of these measures in the LTCF, in most cases, is not proven by prospective controlled studies but is based on infection control logic, adaptation of hospital experience, LTCF surveys, Centers for Disease Control and Prevention (CDC) and other guidelines containing specific recommendations for LTCFs, and field experience. Every effort will be made to address the unique concerns of LTCFs. Because facilities differ, the infection risk factors specific to the resident population, the nature of the facility, and the resources available should dictate the scope and focus of the infection control program.

In a number of instances, specific hospital-oriented guidelines have been published and are referenced (eg, guidelines for prevention of intravascular (IV) device-associated infection). These guidelines are relevant, at least in part, to the LTC setting but may be adapted depending on facility size, resources, resident acuity, local regulations, local infection control issues, etc. Reworking those sources to a form applicable to all LTCFs is beyond the scope of this guideline.

Any discussion of infection control issues must be made in the context of the LTCF as a community. The LTCF is a home for residents, a home in which they usually reside for months or years; comfort and infection control principles must both be addressed.

\section{BACKGROUND}

\section{Demography and definitions}

The US population aged 65 to 85 years is increasing rapidly, and the population aged 85 years and older is expected to double by $2030 .{ }^{4}$ One of every 4 persons who reach the age of 65 can be expected to spend part of his or her life in a nursing home; more people occupy nursing home beds than acute care hospital beds in the US. ${ }^{5}$ Approximately 1.5 million persons in the US reside in a nursing home; there are 15,000 nursing homes in this country. ${ }^{6}$ Ninety percent of nursing home residents are over 65 years of age, and the mean age of residents is over 80 years.

A LTCF is a residential institution for providing nursing care and related services to residents. It may be attached to a hospital (swing-bed) or free standing; the latter is often called a nursing home. A resident is a person living in the LTCF and receiving care, analogous to the patient in a hospital.

\section{Scope of position paper}

This position paper addresses all levels of care in the LTCF. The focus is specifically the LTCF, also known as the nursing home, caring for elderly or chronically ill residents. These recommendations generally also should apply to special extended care situations (such as institutions for the mentally retarded, psychiatric hospitals, pediatric LTCFs, and rehabilitation hospitals). However, other extended care facilities may have different populations (eg, the residents of institutions for the mentally retarded are much younger than nursing home residents), different disease risks (eg, hepatitis B in psychiatric hospitals), or different levels of acuity and technology (eg, higher acuity in long-term acute care facilities or LTACs). Thus, the recommendations may need to be adapted for these special extended care situations.

Changes from prior Guideline. This position paper is similar to the 1997 Society for Healthcare Epidemiology of America (SHEA)/Association for Professionals in Infection Control and Epidemiology (APIC) guideline, ${ }^{7}$ although the present version reflects an updating of research and experience in the field. Several important areas of discussion are new or changed. 


\section{INFECTIONS IN THE LONG-TERM CARE FACILITY}

\section{Epidemiology}

In US LTCFs, 1.6 million to 3.8 million infections occur each year. ${ }^{8}$ In addition to infections that are largely endemic, such as urinary tract infections (UTIs) and lower respiratory tract infections (LRTIs), outbreaks of respiratory and gastrointestinal (GI) infections are also common. ${ }^{9}$ The overall infection rate in LTCFs for endemic infections ranges from 1.8 to 13.5 infections per 1000 resident-care days. ${ }^{8}$ For epidemics, good estimates are difficult to ascertain, but the literature suggests that several thousand outbreaks may occur in US LTCFs each year. ${ }^{8,9}$ The wide ranges of infections and resulting mortality and costs illustrate the challenge in understanding the epidemiology of infections and their impact in LTCFs. There are currently little data and no national surveillance systems for LTCF infections; the estimates have been calculated based on research studies and outbreak reports from the medical literature.

As a part of aging, the elderly have diminished immune response including both phenotypic and functional changes in Tcells. ${ }^{10}$ However, these changes are of limited clinical significance in healthy elderly. Consequently, immune dysfunction in elderly residents of LTCFs is primarily driven by the multiple factors that result in secondary immune dysfunction such as malnutrition, presence of multiple chronic diseases, and polypharmacy, especially with medications that diminish host defenses (eg, immunosuppressants). ${ }^{11,12}$ In addition, LTCF residents often have cognitive deficits that may complicate resident compliance with basic sanitary practices (such as handwashing and personal hygiene) or functional impairments such as fecal and urinary incontinence, immobility, and diminished cough reflex. The elderly nursing home resident is known to have a blunted febrile response to infections. ${ }^{13}$ This parallels other agerelated immunologic abnormalities. A notable fever in this population often signals a treatable infection, such as UTI or aspiration pneumonia.

While the use of urinary catheters in LTCF residents has decreased in recent years, utilization remains around $5 \%$. In LTC residents, the use of invasive devices (eg, central venous catheters, mechanical ventilators, enteral feeding tubes) increases the likelihood of a device-associated infection. Of the over 15,000 LTCFs in the US in 2004, $42 \%$ provided infusion therapy, $22 \%$ had residents with peripherally-inserted central lines, and $46 \%$ provided parenteral nutrition. ${ }^{14}$ Another challenge for preventing infections in LTCFs is the increasing acuity of residents, especially with the rapidly growing subpopulation of postacute residents. Postacute residents are hospitalized patients who are discharged to LTCFs to receive skilled nursing care or physical/occupational therapy. In the past, these patients, often frail, would have remained hospitalized, but, with increasing efforts to control hospital costs, these patients are now discharged to LTCFs. In addition to higher device utilization, these residents are more likely to receive antimicrobial therapy than long-stay LTCF residents. ${ }^{15}$

Much remains to be learned about resident and LTCF factors correlated with HAIs. There is evidence that institutional factors such as nurse turnover, staffing levels, prevalence of Medicare recipients, rates of hospital transfer for infection, intensity of medical services, and family visitation rates are associated with incidence of HAI in the LTC setting. ${ }^{16}$

The rate of deaths in LTCF residents with infections ranges from 0.04 to 0.71 per 1000 resident-days, with pneumonia being the leading cause of death. ${ }^{8}$ Infections are a leading reason for hospital transfer to LTCF residents, and the resulting hospital costs range from $\$ 673$ million to $\$ 2$ billion each year. ${ }^{8}$

LTCFs and acute care facilities differ in another key aspect: LTCFs are residential. As residences, LTCFs are required to provide socialization of residents through group activities. While these activities are important for promoting good physical and mental health, they may also increase communicable infectious disease exposure and transmission. Occupational and physical therapy activities, while vital toward restoring or maintaining physical and mental function, may increase risk for person-to-person transmission or exposure to contaminated environmental surfaces (eg, physical or occupational therapy equipment).

\section{SPECIFIC NOSOCOMIAL INFECTIONS IN THE LONG-TERM CARE FACILITY}

\section{Urinary tract infections}

In most surveys, the leading infection in LTCFs is UTI, ${ }^{17}$ although with restrictive clinical definitions, symptomatic urinary infection is less frequent than respiratory infection. ${ }^{18}$ Bacteriuria is very common in residents of these facilities but, by itself, is not associated with adverse outcomes and does not affect survival. ${ }^{19,20}$ Bacteriuria and UTI are associated with increased functional impairment, particularly incontinence of urine or feces. ${ }^{21,22}$

The symptoms of UTI are dysuria and frequency (cystitis) or fever and flank pain (pyelonephritis). The elderly may present with atypical or nonlocalizing symptoms. Chronic genitourinary symptoms are also common but are not attributable to bacteriuria. ${ }^{20,21}$ 
Because the prevalence of bacteriuria is high, a positive urine culture, with or without pyuria, is not sufficient to diagnose urinary infection. ${ }^{20}$ Clinical findings for diagnosis of UTI in the noncatheterized resident must include some localization to the genitourinary tract. ${ }^{23}$ The diagnosis also requires a positive quantitative urine culture. This is obtained by the clean-catch voided technique, by in and out catheterization, or by aspiration through a catheter system sampling port. A negative test for pyuria or a negative urine culture obtained prior to initiation of antimicrobial therapy excludes urinary infection.

The prevalence of indwelling urethral catheters in the LTCF is $7 \%$ to $10 \% .{ }^{24-26}$ Catheterization predisposes to clinical UTI, and the catheterized urinary tract is the most common source of bacteremia in LTCFs. ${ }^{17,19}$ Residents with long-term catheters often present with fever alone. Residents with indwelling urinary catheters in the LTCF are uniformly colonized with bacteria, largely attributable to biofilm on the catheter. ${ }^{27}$ These organisms are often more resistant to oral antibiotics than bacteria isolated from elderly persons in the community. ${ }^{28,29}$ Catheter-related bacteriuria is dynamic, and antimicrobial treatment only leads to increased antimicrobial resistance. ${ }^{30}$ Thus, it is inappropriate to screen asymptomatic catheterized residents for bacteriuria or to treat asymptomatic bacteriuria. ${ }^{20}$ Specimens collected through the catheter present for more than a few days reflect biofilm microbiology. For residents with chronic indwelling catheters and symptomatic infection, changing the catheter immediately prior to instituting antimicrobial therapy allows collection of a bladder specimen, which is a more accurate reflection of infecting organisms. ${ }^{31}$ Catheter replacement immediately prior to therapy is also associated with more rapid defervescence and lower risk of early symptomatic relapse posttherapy. ${ }^{31}$

Guidelines for prevention of catheter-associated UTIs in hospitalized patients ${ }^{32}$ are generally applicable to catheterized residents in LTCFs. Recommended measures include limiting use of catheters, insertion of catheters aseptically by trained personnel, use of as small diameter a catheter as possible, handwashing before and after catheter manipulation, maintenance of a closed catheter system, avoiding irrigation unless the catheter is obstructed, keeping the collecting bag below the bladder, and maintaining good hydration in residents. Urinary catheters coated with antimicrobial materials have the potential to decrease UTIs but have not been studied in the LTCF setting. For some residents with impaired voiding, intermittent catheterization is an option, and clean technique is as safe as sterile technique. ${ }^{33}$ External catheters are also a risk factor for UTIs in male residents ${ }^{34}$ but are significantly more comfortable and associated with fewer adverse effects, including symptomatic urinary infection, than an indwelling catheter. ${ }^{35}$ Local external care is required. The CDC guideline ${ }^{32}$ briefly discusses care of condom catheters and suprapubic catheters, but no guideline for leg bags is available. Leg bags allow for improved ambulation of residents but probably increase the risk of UTI because opening of the system and reflux of urine from the bag to the bladder occur more frequently than with a standard closed system. Suggestions for care of leg bags include using aseptic technique when disconnecting and reconnecting, disinfecting connections with alcohol, changing bags at regular intervals, rinsing with diluted vinegar, and drying between uses. ${ }^{36}$ A 1:3 dilution of white vinegar has been recommended for leg bag disinfection. ${ }^{37}$

\section{Respiratory tract infections}

Because of the impaired immunity of elderly persons, viral upper respiratory infections (URIs) that generally are mild in other populations may cause significant disease in the institutionalized elderly patient. $^{38,39}$ Examples include influenza, respiratory syncytial virus (RSV), parainfluenza, coronavirus, rhinoviruses, adenoviruses, and recently discovered human metapneumovirus. ${ }^{40}$

Pneumonia. Pneumonia or lower respiratory tract infection (LRTI) is the second most common cause of infection among nursing home residents, with an incidence ranging from 0.3 to 2.5 episodes per 1000 resident care-days and is the leading cause of death from infections in this setting. Elderly LTCF residents are predisposed to pneumonia by virtue of decreased clearance of bacteria from the airways and altered throat flora, poor functional status, presence of feeding tubes, swallowing difficulties, and aspiration as well as inadequate oral care. ${ }^{41-43}$ Underlying diseases, such as chronic obstructive pulmonary disease and heart disease, further increase the risk of pneumonia in this population. ${ }^{44}$ The clinical presentation of pneumonia in the elderly often is atypical. While there is a paucity of typical respiratory symptoms, recent studies have shown that fever is present in $70 \%$, new or increased cough in $61 \%$, altered mental status in $38 \%$, and increased respiratory rate above 30 per minute in $23 \%$ of residents with pneumonia. ${ }^{45}$

While acquiring a diagnostic sputum can be difficult, obtaining a chest radiograph is now more feasible than in the past. In general it is recommended that a pulse oximetry, chest radiograph, complete blood count with differential, and blood urea nitrogen should be obtained in residents with suspected pneumonia. ${ }^{46}$ Streptococcus pneumoniae appears to be the most common etiologic agent accounting for about $13 \%$ of all cases, ${ }^{47,48}$ followed by Hemophilus influenzae $(6.5 \%)$, 
Staphylococcus aureus (6.5\%), Moraxella catarrhalis $(4.5 \%)$, and aerobic gram-negative bacteria $(13 \%){ }^{44}$ Legionella pneumoniae also is a concern in the LTCF. Colonization with methicillin-resistant $S$ aureus (MRSA) and antibiotic-resistant, gram-negative bacteria further complicate diagnosis and management of pneumonia in LTCF residents. ${ }^{49,50}$

The mortality rate for LTCF-acquired pneumonia is significantly higher than for community-acquired pneumonia in the elderly population. ${ }^{51}$ Preinfection functional status, dementia, increased rate of respirations and pulse, and a change in mental status are considered to be poor prognostic factors. Several indices predictive of mortality have been developed and may be useful in managing residents with pneumonia. ${ }^{45,52,53}$

The CDC guideline for prevention of pneumonia ${ }^{54}$ is oriented toward acute care hospitals but covers a number of points relevant to the LTCF, including respiratory therapy equipment, suctioning techniques, tracheostomy care, prevention of aspiration with enteral feedings, and immunizations. Examples of relevant recommendations for the LTCF include hand hygiene after contact with respiratory secretions, wearing gloves for suctioning, elevating the head of the bed 30 to 45 degrees during tube feeding and for at least 1 hour after to decrease aspiration, and vaccination of high-risk residents with pneumococcal vaccine. ${ }^{54}$ The evidence for the efficacy of pneumococcal vaccine in high-risk populations, including the elderly population, is debated. ${ }^{55,56}$ However, the vaccine is safe, relatively inexpensive, and recommended for routine use in individuals over the age of 65 years. ${ }^{56,57}$ Pneumococcal vaccination rates for a facility are now publicly reported at the Centers for Medicare and Medicaid Services (CMS). ${ }^{58}$

Influenza. Influenza is an acute respiratory disease signaled by the abrupt onset of fever, chills, myalgias, and headache along with sore throat and cough, although elderly LTCF residents may not have this typical presentation. The incubation period for influenza is approximately 1 to 2 days. ${ }^{59}$ It is a major threat to LTCF residents, who are among the high-risk groups deserving preventive measures. ${ }^{60}$ Influenza is very contagious, and outbreaks in LTCFs are common and often severe. Clinical attack rates range from $25 \%$ to $70 \%$, and case fatality rates average over $10 \% .{ }^{61-64}$

A killed virus vaccine is available but must be given annually. Influenza vaccine in the elderly is approximately $40 \%$ effective at preventing hospitalization for pneumonia and approximately $50 \%$ effective at preventing hospital deaths from pneumonia. ${ }^{65}$ Although concern has been expressed regarding the efficacy of the influenza vaccine in institutionalized elderly patients, most authors feel that the influenza vaccine is effective and indicated for all residents and caregivers. ${ }^{63-68}$ Recent surveys have shown an increased rate of influenza vaccination among LTCF residents, although significant variability exists. ${ }^{69,70}$ Influenza vaccination rates for a facility are now publicly reported at the Centers for Medicare and Medicaid (CMS) Web site http://www.medicare.gov/NHCompare/ home.asp. Staff immunization rates remain less impressive, with average immunization rates between $40 \%$ and $50 \%$ at best.

While viral cultures from nasopharynx remain the gold standard for diagnosis of influenza, several rapid diagnostic methods (rapid antigen tests) such as immunofluorescence or enzyme immunoassay have been developed. These tests detect both influenza A and B viral antigens from respiratory secretions. Amantadine-resistant influenza has caused LTCF outbreaks and hence amantadine is not recommended for influenza prophylaxis. ${ }^{71}$ Zanamivir and oseltamivir are effective against both influenza $A$ and $B$ and have been approved for prophylaxis and treatment of influenza $A$ and $B$. Oseltamivir is administered orally and is excreted in the urine requiring dose adjustments for renal impairment. Zanamivir is given by oral inhalation, which is a problem in a noncooperative LTCF resident.

Rapid identification of cases in order to promptly initiate treatment and isolate them to prevent transmission remains the key to controlling influenza outbreaks. Other measures recommended during an outbreak of influenza include restricting admissions or visitors and cohorting of residents with influenza. ${ }^{60,72,73}$ Infected staff should not work.

Tuberculosis. Tuberculosis (TB) also has caused extensive outbreaks in LTCFs, generally traced to a single ambulatory resident. Large numbers of staff and residents may be involved, with a potential to spread in the community. ${ }^{74-76}$ Price and Rutala ${ }^{77}$ found $8.1 \%$ of new employees and $6.4 \%$ of new residents to be positive by the purified protein derivative (PPD) of tuberculin method in their North Carolina survey, with significant 5-year skin test conversion rates in both groups.

The diagnosis of TB in the LTCF is problematic. Clinical signs (fever, cough, weight loss) are nonspecific. Chest radiographs, when obtained, often show characteristic pulmonary infiltrates (eg, cavities in the upper lung fields). Infection with TB usually causes a positive tuberculin skin test (TST), although occasional false positives and false negatives are seen. The specificity of the TST may be improved by an in vitro blood test of interferon release in response to TB peptides, such as the quantiferon test. The most specific diagnostic test is a sputum culture for $\mathrm{TB}$, but a good specimen may be difficult to obtain. Recent advances in microbiology have facilitated the diagnosis of TB greatly. Diagnostics such as radiometric systems, polymerase chain 
reaction (PCR), as well as specific DNA probes help shorten the time for diagnosis of TB, although susceptibility testing requires several weeks.

Guidelines discussing standards for control of TB in institutions are available. ${ }^{78-81}$ There appears to be a consensus that TST of residents and personnel in the LTCF should be undertaken on a regular basis, although many LTCFs have inadequate TB screening programs. ${ }^{82}$ The cost-effectiveness of using a 2-step TST to survey for the booster effect is not demonstrable for all populations, but the 2-step skin test is recommended by the CDC for initial screening of employees and residents. For LTCF residents without any known contact with a case of known TB or other significant risk factors such as human immunodeficiency virus (HIV) or immunosuppression, induration of $10 \mathrm{~mm}$ or greater to PPD injection is considered positive. Induration of $5 \mathrm{~mm}$ or greater is considered positive in any individual with recent contact with a known case of TB or other significant risk factors such as immunosuppression or changes on chest $\mathrm{x}$-ray consistent with old TB. ${ }^{83}$

There was a resurgence of TB in the US in the mid1980s; multidrug-resistant cases of TB have been seen, and nosocomial spread within health care facilities is a concern. ${ }^{84}$ In response to this, guidelines have been promulgated by the $\mathrm{CDC}$ that address surveillance (identification and reporting of all TB cases in the facility including residents and staff); containment (recommended treatment under directly observed therapy and appropriate respiratory isolation and ventilation control measures); assessment (monitoring of surveillance and containment activities); and ongoing education of residents, families, and staff. ${ }^{85}$ Since most LTCFs do not have a negative-pressure room, residents with suspected active TB should be transferred to an appropriate acute care facility for evaluation. There should be a referral agreement with that facility.

\section{Skin and soft-tissue infections, infestations}

Pressure ulcers (also termed decubitus ulcers) occur in up to $20 \%$ of residents in LTCFs and are associated with increased mortality. ${ }^{86-88}$ Infected pressure ulcers often are deep soft-tissue infections and may have underlying osteomyelitis; secondary bacteremic infections have a $50 \%$ mortality rate. ${ }^{88}$ They require costly and aggressive medical and surgical therapy. Once infected, pressure ulcer management requires a multidisciplinary approach with involvement of nursing, geriatrics and infectious disease specialists, surgery, and physical rehabilitation.

Medical factors predisposing to pressure ulcers have been delineated ${ }^{86}$ and include immobility, pressure, friction, shear, moisture, incontinence, steroids, malnutrition, and infection. Reduced nursing time can also increase the risk of developing pressure ulcers. Several of these factors may be partially preventable (such as malnutrition and fecal incontinence). Prevention of pressure ulcers involves developing a plan for turning, positioning, eliminating focal pressure, reducing shearing forces, and keeping skin dry. Attention to nutrition, using disposable briefs and identifying residents at a high risk using prediction tools can also prevent new pressure ulcers.

The goals are to treat infection, promote wound healing, and prevent future ulcers. Many physical and chemical products are available for the purpose of skin protection, debridement, and packing, although controlled studies are lacking in the area of pressure ulcer prevention and healing. ${ }^{89} \mathrm{~A}$ variety of products may be used to relieve or distribute pressure (such as special mattresses, kinetic beds, or foam protectors) or to protect the skin (such as films for minimally draining stage II ulcers, hydrocolloids and foams for moderately draining wounds, alginates for heavily draining wounds). Negative-pressure wound therapy (vacuum dressings) using gentle suction to provide optimal moist environment is increasingly being used in treatment of complex pressure ulcers. ${ }^{90}$ Nursing measures such as regular turning are essential as well. A pressure ulcer flow sheet is a useful tool in detecting and monitoring pressure ulcers and in recording information such as ulcer location, depth, size, stage, and signs of inflammation as well as in timing of care measures. Infection control measures include diligent hand hygiene and glove usage.

Because all pressure ulcers, like the skin, are colonized with bacteria, antibiotic therapy is not appropriate for a positive surface swab culture without signs and symptoms of infection. Nonintact skin is more likely to be colonized with pathogens. True infection of a pressure ulcer (cellulitis, osteomyelitis, sepsis) is a serious condition, generally requiring broadspectrum parenteral antibiotics and surgical debridement in an acute care facility.

Cellulitis (infection of the skin and soft tissues) can occur either at the site of a previous skin break (pressure ulcer) or spontaneously. Skin infections generally are caused by group A streptococci or $S$ aureus. Outbreaks of group A streptococcal infections have been described, presenting as cellulitis, pharyngitis, pneumonia, or septicemia. ${ }^{91-93}$

Scabies is a contagious skin infection caused by a mite. Lesions usually are very pruritic, burrow-like, and associated with erythema and excoriations, usually in interdigital spaces of the fingers, palms and wrists, axilla, waist, buttocks, and the perineal area. However, these typical findings may be absent in debilitated residents, leading to large, prolonged outbreaks in LTCFs. ${ }^{94-96}$ Diagnosis in an individual with a rash 
requires a high index of suspicion in order to recognize the need for diagnostic skin scrapings. The presence of a proven case should prompt a thorough search for secondary cases. A single treatment with permethrin or lindane usually is effective, but repeated treatment or treatment of all LTCF residents, personnel, and families occasionally is necessary. ${ }^{97,98}$ Ivermectin, an oral antihelminthic agent, is an effective, safe, and inexpensive option for treatment of scabies. However, it has not been approved by the FDA for this indication. Therapy of rashes without confirming the diagnosis of scabies unnecessarily exposes residents to the toxic effects of the topical agents. Because scabies can be transmitted by linen and clothing, the environment should be cleaned thoroughly. This includes cleaning inanimate surfaces, hot-cycle washing of washable items (clothing, sheets, towels, etc), and vacuuming the carpet.

\section{Other infections}

Viral gastroenteritis (caused by rotavirus, enteroviruses, or noroviruses), ${ }^{99,100}$ bacterial gastroenteritis (caused by Clostridium difficile, Bacillus cereus, Escherichia coli, Camplylobacter spp, C perfringens, or Salmonella spp), and parasites (such as Giardia lambia) are well-known causes of diarrhea outbreaks in LTCFs. ${ }^{\text {101-106 }}$

The elderly are at increased risk of infectious gastroenteritis due to age-related decrease in gastric acid. In a population with a high prevalence of incontinence, the risk of cross infection is substantial. Person-to-person spread, particularly due to shared bathroom, dining, and rehabilitation facilities, plays a role in viral gastroenteritis and in Shigella spp and $C$ difficile diarrhea. ${ }^{107}$ Foodborne disease outbreaks also are very common in this setting, ${ }^{108}$ most often caused by Salmonella spp or $S$ aureus. E coli O157:H7 and Giardia also may cause foodborne outbreaks, underscoring the importance of proper food preparation and storage.

Bacteremia ${ }^{109-111}$ in the LTCF, although rarely detected, may be primary or secondary to an infection at another site (pneumonia, UTI). The most common source of secondary bacteremia is the urinary tract, with $E$ coli being the culprit in over $50 \%$ of cases. ${ }^{109,111}$ As the acuity of illness in LTCF residents has risen, the prevalence of IV devices and related bacteremic complications appears to have increased. The CDC guideline for prevention of IV infections is a useful resource and generally applicable to the LTCF. ${ }^{112}$ Relevant points include aseptic insertion of the IV cannula, daily inspection of the IV for complications such as phlebitis, and quality control of IV fluids and administration sets.

Conjunctivitis in the adult presents as ocular pain, redness, and discharge. In the LTCF, cases may be sporadic or outbreak-associated. ${ }^{113}$ Many cases are nonspecific or of viral origin; $S$ aureus appears to be the most frequent bacterial isolate. ${ }^{114}$ Epidemic conjunctivitis may spread rapidly through the LTCF. Transmission may occur by contaminated eye drops or hand cross contamination. Gloves should be worn for contact with eyes or ocular secretions, with hand hygiene performed immediately after removing gloves.

Many additional infections have been encountered in the LTCF, including herpes zoster, herpes simplex, endocarditis, viral hepatitis, septic arthritis, and abdominal infections. There has been a resurgence of "pediatric" infections in the LTCF (eg, pertussis, RSV, and H influenzae respiratory tract infections), reflecting the decline of the host's immunologic memory with aging

\section{Epidemic infections in the LTCF}

Most LTCF HAIs are sporadic. Many are caused by colonizing organisms with relatively low virulence. Tissue invasion may be facilitated by the presence of a urinary catheter or chronic wound or following an aspiration event. Ongoing surveillance (see Surveillance section below) is required to detect epidemic clustering of transmissible, virulent infections. Outbreaks must be anticipated. Ideally, infection control surveillance and practices should be the responsibility of frontline staff as well as infection control staff.

An outbreak or transmission within the facility may occur explosively with many clinical cases appearing within a few days or may, for example, involve an unusual clustering of MRSA clinical isolates on a single nursing unit over several months. On the other hand, a case of MRSA infection may follow a prolonged period of asymptomatic nasal colonization after an aspiration event or development of a necrotic wound. ${ }^{115}$

Outbreaks in LTCFs accounted for a substantial proportion (15\%) of reported epidemics ${ }^{116}$ (Table 1). Clustering of URIs, diarrhea, skin and soft tissue infection, conjunctivitis, and antibiotic-resistant bacteriuria have been noted. ${ }^{9}$ Major outbreaks of infection have also been ascribed to $E$ coli, ${ }^{117}$ group A streptococci, ${ }^{92,118}$ C difficile ${ }^{104,119}$ respiratory viruses, ${ }^{38}$ Salmonella spp, ${ }^{120}$ Chlamydia pneumoniae ${ }^{121,122}$ Legionella spp, ${ }^{123}$ and gastrointestinal viruses. ${ }^{124}$ Nursing homes accounted for $2 \%$ of all foodborne disease outbreaks reported to the CDC $(1975-1987)$ and $19 \%$ of outbreak-associated deaths. ${ }^{125}$ Transmissible gastrointestinal pathogens may be introduced to the facility by contaminated food or water or infected individuals. High rates of fecal incontinence, as well as gastric hypochlorhydria, make the nursing home ideal for secondary fecal-oral transmission. ${ }^{126}$ Other epidemics include scabies, hepatitis $\mathrm{B},{ }^{127}$ group A streptococcal infections, viral conjunctivitis, and many other infections. 
Table I. Common long-term care facility epidemics

\begin{tabular}{l}
\hline Respiratory: \\
Influenza \\
Tuberculosis \\
S pneumoniae \\
Chlamydia pneumoniae \\
Legionella spp \\
Other respiratory viruses (Parainfluenza, RSV) \\
Gastrointestinal: (may be foodborne) \\
Viral gastroenteritis (Norovirus, etc) \\
Clostridium difficile \\
Salmonellosis \\
E coli OI57:H7 colitis \\
Other infections: \\
Methicillin-resistant Staphylococcus aureus (MRSA) \\
Vancomycin-resistant Enterococcus (VRE) \\
Group A Streptococcus \\
Scabies \\
Conjunctivitis \\
\hline
\end{tabular}

These outbreaks underscore the vulnerability of the elderly to infection, as well as the role of cross infection in residents with urinary catheters and open wounds or in those with incontinence who require serial contact care by staff. ${ }^{120}$ In addition, mobile residents with poor hygiene may interact directly.

\section{Antibiotic-resistant bacteria}

Multidrug resistant organisms (MDROs) such as MRSA, vancomycin-resistant enterococci (VRE), drugresistant $S$ pneumoniae, and multidrug-resistant gramnegative bacteria (eg, Pseudomonas aeruginosa, Acinetobacter spp and extended-spectrum $\beta$-lactamase (ESBL)-producing enterobacteriaceae) are increasingly important causes of colonization and infection in LTCFs. ${ }^{128-137}$ In this setting, infection with MDROs has been associated with increased morbidity, mortality, and cost, ${ }^{138,139}$ although the attributable morbidity, mortality, and cost of MDROs has not yet been fully defined. Indeed, LTCF residence has been frequently identified as a risk factor for antibiotic-resistant infection in hospitalized patients. ${ }^{140,141}$

Elderly and disabled residents are at increased risk for colonization with resistant organisms, and colonization may persist for long periods of time (ie, months to years). ${ }^{133,142-146}$ Within the LTCF, length of stay in the facility and accommodation in rooms with multiple beds have been identified as risk factors for transmission of MRSA. ${ }^{147}$ Both infected and colonized residents may serve as sources for the spread of MDROs in the LTCF. $^{135,148}$ When MRSA becomes endemic within a facility, elimination is highly unlikely. ${ }^{148}$ LTCFs can expect infections with MDROs to be a continuing problem. Strategies for curbing the emergence and spread of antimicrobial resistance in LTCFs are discussed below in "Antibiotic Stewardship" and "Isolation and Precautions" sections.

\section{THE INFECTION CONTROL PROGRAM}

\section{Evolution of programs}

The 1980s saw a dramatic increase in LTCF infection control activities, stimulated by federal and state regulations. Several studies provide insight into the extent of program development. A 1981 survey of Utah LTCFs $^{113}$ noted that all facilities had regular infection control meetings, but none performed systematic surveillance for infections or conducted regular infection control training. All LTCFs had policies regarding the maintenance and care of urinary catheters, although the policies were not uniform. Price et $\mathrm{al}^{149}$ surveyed 12 North Carolina LTCFs in 1985 and found that, although all 12 had a designated ICP, none of the ICPs had received special training in this area. Also noted were deficiencies in isolation facilities, particularly an insufficient number of sinks and recirculated, inadequately filtered air.

In a 1985 survey of Minnesota LTCFs, Crossley et $\mathrm{al}^{150}$ found that the majority had an infection control committee (ICC) and a designated ICP, although substantial deficiencies in resident and employee health programs occurred. For instance, only $61 \%$ offered the influenza vaccine to residents, and one third did not screen new employees for a history of infectious disease problems. A 1988 Maryland survey ${ }^{151}$ found that one third of nursing homes still performed routine environmental cultures, and many lacked proper isolation policies. In 1990, a survey of Connecticut LTCFs found that most ICPs had received some training in infection control. ${ }^{152,153}$ Most LTCFs performed surveillance at least weekly, and most used written criteria to determine HAIs.

More recent regional surveys of facilities from Maryland and New England in the mid-1990s and Michigan in 2005 noted increasing gains in time spent in infection control activities from 1994 to $2005 .{ }^{69,154}$ In New England, $98 \%$ of facilities had a person designated to do infection control, $90 \%$ were registered nurses, and $52 \%$ had formal training. ${ }^{154}$ In the 1990 s, an average of 9 to 12 hours per week was spent on infection control; $50 \%$ to $54 \%$ of that time was spent on surveillance activities. ${ }^{154}$ Seventy-eight to $97 \%$ percent of the LTCFs reported a systematic surveillance system. ${ }^{69}$ Formal definitions were used by $95 \%$ of respondents; $81 \%$ used the McGeer criteria, and 59\% calculated infection rates. ${ }^{154}$ All facilities reportedly used Universal Precautions in caring for their residents. ${ }^{154}$

By $2005,50 \%$ of responding facilities in Michigan had a full-time ICP. ${ }^{69}$ The mean time spent on infection 
control activities by the infection control staff varied from 40 hours per week for full-time ICPs to 15 hours per week for part-time staff. ${ }^{69}$ However, part-time ICPs did not necessarily supervise smaller facilities with fewer subacute care beds or give fewer in-services than full-time staff.

Despite these improvements, the number of ICPs per nursing home bed is 4-fold fewer than the number of ICPs available in acute care hospitals. ${ }^{155}$ LTCF-based ICPs are more likely to assume noninfection control functions than acute care ICPs regardless of bed size; in one survey, $98 \%$ of LTCF ICPs had other duties, ${ }^{156}$ while in a Michigan survey, $50 \%$ of 34 LTCFs had fulltime ICPs. ${ }^{69}$ Many of these noninfection control functions include employee health, staff education and development, and quality improvement. ${ }^{155}$ In addition, LTCF ICPs are still less likely to receive additional formal training in infection control (8\%) compared with $95 \%$ of acute care ICPs. ${ }^{155}$ The results of this study from Maryland led to a state proposal that at least one ICP from each LTCF be formally trained in infection control. ${ }^{155}$

From these surveys, one can develop a composite picture of the LTCF ICP as a nurse who still has not necessarily received formal training in infection control. ${ }^{154,155}$ Many ICPs still work part-time on infection control activities regardless of the number of beds or patient acuity. ${ }^{69,155}$ While the time spent on infection control activities appears to have increased significantly from 36 to 48 hours per month in the 1990s to 90 to 160 hours per month in 2005, the ICP continues to have other duties such as general duty nursing, nursing supervision, in-service education, employee health, and quality assurance..$^{34,69,154}$

\section{Regulatory aspects}

LTCFs are covered by federal and state regulations as well as voluntary agency standards such as those written by The Joint Commission (TJC). ${ }^{157}$ Skilled nursing facilities are required by the Omnibus Budget Reconciliation Act of 1987 (OBRA) to have an infection control program. ${ }^{158}$ CMS has published requirements for LTCFs $^{159}$ that apply to LTCFs accepting Medicare and/ or Medicaid residents. CMS regulations address the need for a comprehensive infection control program that includes surveillance of infections; implementation of methods for preventing the spread of infections including use of appropriate isolation measures, employee health protocols, hand hygiene practices; and appropriate handling, processing, and storage of linens. ${ }^{160,161}$ For example, the LTCF is required to establish and maintain an infection control program designed to provide a safe, sanitary, and comfortable environment and to help prevent the development and transmission of disease and infection. Interpretive guidelines for surveyors further discuss definitions of infection, risk assessment, outbreak management and control, measures for preventing specific infections, staff orientation, antibiotic monitoring, sanitation, and assessment of compliance with infection control policies. ${ }^{161}$

Because the LTCF is an employer of health care workers (HCWs), it must comply with federal and/or state OSHA regulations. For infection control, those regulations ${ }^{162,163}$ deal primarily with protection of workers from exposure to bloodborne pathogens such as HIV, hepatitis B virus (HBV), and hepatitis C virus (HCV) and from TB exposure. ${ }^{85}$ Adherence of LTCFs to infection control regulations is an OSHA priority.

Other standards that apply to LTCFs include the federal minimum requirements for design, construction, and equipment ${ }^{164}$ and TJC LTC Standards. ${ }^{165}$ The 2007 TJC Standards for LTC require a written infection control plan based on an assessment of risk; establishment of priorities, goals, and strategies; and an evaluation of the effectiveness of the interventions. The Standards also deal with managing an influx of patients with an infectious disease as well as leadership's involvement in the program. ${ }^{165}$ In addition, many states have statutory requirements for LTCFs that vary widely.

On October 7, 2005, CMS published a final rule requiring LTCFs to offer annually to each resident immunization against influenza and to offer lifetime immunization against pneumococcal disease. LTCFs are required to ensure that each resident or legal representative receive education on the benefits and potential side effects of the immunizations prior to their being administered. ${ }^{58}$ The LTCF administrative staff should be knowledgeable about the federal, state, and local regulations governing infection control in order to implement and maintain a program in compliance with these regulations. The LTCF ICP ideally should be involved in the formation and revision of regulations, through local and national infection control and long-term care organizations, to help assure the scientific validity of the regulations.

Experts in infection control in Canada have called for 1 full-time formally trained ICP per 150 to 250 long-term beds. ${ }^{166}$ The Consensus Panel from SHEA and APIC has recommended that nonhospital facilities including LTCFs provide adequate resources in terms of personnel, education, and materials to ICPs to fulfill their functions. ${ }^{167}$ While most of the current information has been derived from facilities serving older populations in North America, reports from LTCFs in Europe and Australia and those serving pediatric populations are increasing. ${ }^{168-171}$ 
Table 2. Long-term care facility infection control program: structure

\begin{tabular}{|c|c|c|}
\hline Leadership & Expertise/training & Role(s) \\
\hline \multicolumn{3}{|c|}{ Infection Control Committee/Oversight Committee } \\
\hline Core members & Administration, Nursing Representative, Medical Director, ICP & $\begin{array}{l}\text { Identifies areas of risk } \\
\text { Establishes priorities }\end{array}$ \\
\hline Ad hoc members & $\begin{array}{l}\text { Food Service, Maintenance, Housekeeping, Laundry Services, } \\
\text { Clinical Services, Resident Activities, Employee Health }\end{array}$ & $\begin{array}{l}\text { Plans strategies to achieve goals } \\
\text { Implements plans } \\
\text { Develops policies/procedures } \\
\text { Allocates resources } \\
\text { Assesses program efficacy at least annually }\end{array}$ \\
\hline \multicolumn{3}{|c|}{ Infection Control Professional } \\
\hline ICP & Qualification via education, experience, certification & $\begin{array}{l}\text { Surveillance } \\
\text { Data collection and analysis } \\
\text { Implementation of policies, procedures } \\
\text { Education } \\
\text { Reporting to oversight group/ICC } \\
\text { Communication to public health } \\
\text { Communication to other agencies } \\
\text { Communication to other facilities }\end{array}$ \\
\hline
\end{tabular}

\section{Infection control program elements}

The structure and components of an infection control program are shown in Tables 2 and 3, respectively. Several authors have discussed the components of an infection control program in the LTCF. ${ }^{34,36,166,167,172-177}$ These components generally are drawn from regulatory requirements, current nursing home practices, and extrapolations from hospital programs. The limited resources of most LTCFs affect the type and extent of programs developed. ${ }^{173}$ Most authors feel that an infection control program should include some form of surveillance for infections, an epidemic control program, education of employees in infection control methods, policy and procedure formation and review, an employee health program, a resident health program, and monitoring of resident care practices. The program also may be involved in quality improvement, patient safety, environmental review, antibiotic monitoring, product review and evaluation, litigation prevention, resident safety, preparedness planning, and reporting of diseases to public health authorities.

\section{The ICP}

An ICP is an essential component of an effective infection control program and is the person designated by the facility to be responsible for infection control (see Table 2), The ICP usually is a staff nurse, a background that is helpful for resident assessment and chart review. The ICP most commonly is a registered nurse. Because of size and staffing limitations, the vast majority of LTCF ICPs have other duties, such as assistant director of nursing, charge nurse, in-service coordinator, employee health, or performance improvement. The number of LTCF beds justifying a full-time ICP is unknown and usually depends on the acuity level of residents and the level of care provided. A LTCF with more than 250 to 300 beds may need a fulltime ICP. The LTCF ICP, like the hospital ICP, requires specific training in infection control; well-defined support from administration; and the ability to interact tactfully with personnel, physicians, and residents.

APIC and the Community and Hospital Infection Control Association-Canada (CHICA-Canada) have developed professional and practice standards for infection control and epidemiology that address education including qualifications and professional development for the ICP. ${ }^{178}$ These standards may not represent the current education and qualifications of ICPs in many LTCFs, but they serve as a benchmark for which LTC ICPs and their facilities can strive.

The qualifications include 3 criteria for entering the profession. The ICP:

- Has knowledge and experience in areas of resident care practices, microbiology, asepsis, disinfection/ sterilization, adult education, infectious diseases, communication, program administration, and epidemiology;

- has a baccalaureate degree (the minimum educational preparation for the role); and

- attends a basic infection control training course within the first year of entering the profession.

The criteria for professional development include the ICP maintaining current knowledge and skills in the area of infection prevention, control, and epidemiology. The professional development standards include 5 criteria. The ICP: 
Table 3. Long-term care facility infection control program: elements

\begin{tabular}{|c|c|}
\hline Elements & Examples \\
\hline \multicolumn{2}{|l|}{ Infection control activities } \\
\hline Establish and implement & Hand hygiene \\
\hline routine infection control & Standard precautions \\
\hline \multirow[t]{2}{*}{ policies and procedures } & Organism-specific isolation \\
\hline & Employee education \\
\hline \multirow[t]{3}{*}{ Infection identification } & Develop case definitions \\
\hline & Establish endemic rates \\
\hline & Establish outbreak thresholds \\
\hline \multicolumn{2}{|l|}{$\begin{array}{l}\text { Identification, investigation, } \\
\text { and control of outbreaks }\end{array}$} \\
\hline Organism-specific infection control & Influenza \\
\hline \multirow[t]{3}{*}{ policies and procedures } & $\mathrm{TB}$ \\
\hline & Scabies \\
\hline & MDROs (eg, MRSA) \\
\hline \multirow[t]{3}{*}{ Disease reporting } & Public health authorities \\
\hline & Receiving institutions \\
\hline & LTCF staff \\
\hline Antibiotic stewardship & Review of antimicrobial use \\
\hline \multirow[t]{2}{*}{ Monitoring of patient care practices } & Aspiration precautions \\
\hline & $\begin{array}{l}\text { Pressure ulcer prevention } \\
\text { Invasive device care and use }\end{array}$ \\
\hline \multirow[t]{9}{*}{ Facility management issues } & General maintenance \\
\hline & Plumbing/ventilation \\
\hline & Food preparation/storage \\
\hline & Laundry collection/cleaning \\
\hline & $\begin{array}{l}\text { Infectious waste collection/ } \\
\text { disposal }\end{array}$ \\
\hline & Environment \\
\hline & Housekeeping/cleaning \\
\hline & Disinfection/sanitation \\
\hline & Equipment cleaning \\
\hline Product evaluation & Single use devices \\
\hline \multirow[t]{2}{*}{ Resident health program } & TB screening \\
\hline & Immunization program \\
\hline \multirow[t]{3}{*}{ Employee health program } & TB screening \\
\hline & Immunizations \\
\hline & Occupational exposures \\
\hline \multicolumn{2}{|l|}{ Other program elements } \\
\hline Performance improvement & Serve on PI committee \\
\hline Resident safety & Study preventable adverse events \\
\hline Preparedness planning & $\begin{array}{l}\text { Develop pandemic influenza } \\
\text { preparedness plan }\end{array}$ \\
\hline
\end{tabular}

- Becomes certified in infection control within 5 years of entry into the profession and maintains certification;

- advances knowledge and skills through continuing education;

- pursues formal education in health care epidemiology;

- maintains a knowledge base of current infection prevention and control information through peer networking, Internet access, published literature, and/or professional meetings; and

- advances the field of infection prevention and control and epidemiology through support of related research.

\section{The infection control oversight committee}

The regulatory requirement for a formal LTCF ICC was dropped by OBRA at the federal level, but some states still require them. ${ }^{174}$ The ICP should be familiar with state regulations. This committee frequently has been less active than the corresponding ICC in the hospital setting, in part because of decreased physician availability. A small working group (the infection control oversight committee) consisting of the ICP, the administrator, the medical director, and the nursing supervisor or their designee may efficiently make most of the infection control decisions (Table 2). The ICC functions may be merged with the performance improvement or patient safety programs, but infection control must remain identifiable as a distinct program. Whatever group is selected to oversee the infection control program, it should meet regularly to review infection control data, review policies, and monitor program goals and activities. Written records of meetings should be kept.

The LTCF administrative staff should support the ICP with appropriate educational opportunities and resources, including expert consultation in infectious diseases and infection control as needed. The participation of an infectious diseases (ID) physician or other health care professional with training or experience in infection control should be available on at least a consultative basis. Information may be obtained from SHEA (www.shea-online.org or 703-684-1006). The local health department may have useful information, and local ICPs are another valuable source of information, available from the APIC at www.apic.org.

\section{Educational opportunities for ICPs}

Courses are available for ICPs and health care epidemiologists. SHEA offers jointly sponsored courses in health care epidemiology and infection control for individuals with different levels of experience. The SHEA/CDC course is for physicians and others with advanced training who wish to increase their expertise in infection control. The SHEA/Infectious Diseases Society of America (IDSA)/Johns Hopkins University School of Medicine of America course is designed primarily for ID physicians in training. Similar courses are offered in Europe through SHEA and the European Society for Clinical Microbiology and Infectious Diseases (www.shea-online.org or 703-6841006). APIC offers a training course for hospital and LTCF infection control professionals (www.apic.org or 202-789-1890). The Nebraska Infection Control Network offers regular 2-day basic training courses specifically for LTCF ICPs (www.nicn.org), and other local courses are available. 


\section{Surveillance}

Infection surveillance in the LTCF involves the systematic collection, consolidation, and analysis of data on HAIs. Standardization of surveillance is desirable. To facilitate standardization, resources that include practice guidance for surveillance identifying seven recommended steps are available. These steps are (1) assessing the population, (2) selecting the outcome or process for surveillance, (3) using surveillance definitions, (4) collecting surveillance data, (5) calculating and analyzing infection rates, (6) applying risk stratification methodology, and (7) reporting and using surveillance information. ${ }^{179}$

Assessing the population. Infection surveillance may either include all residents in a facility (total house surveillance) or be targeted at specific subpopulations. Although facility-wide surveillance is useful for calculating baseline rates and detecting outbreaks, a more focused analysis could include examination of infection rates in residents who are at risk for certain kinds of infection (such as aspiration pneumonia in residents receiving tube feedings or bloodstream infection among residents with indwelling vascular catheters). Focused surveillance should target infections that are preventable; that occur frequently; and that are associated with significant morbidity, mortality, and cost. Facility-wide surveillance is useful for establishing an infection control "presence" in the LTCF and may be required as a part of local or state regulatory programs. To establish baseline infection rates, track progress, determine trends, and detect outbreaks, site-specific rates should be calculated (eg, central line infections per 1000 central line-days). Routine analysis should try to explain the variation in site-specific rates. For example, a change in the rate might be related to a change in the resident population. Focused or highrisk resident surveillance may permit conservation of resources, although in many small institutions whole house surveillance is feasible.

Selecting the outcome measures. Traditionally surveillance in the LTCF refers to collection of data on outcome measures such as HAIs that occur within the institution (eg, incidence of UTI or central lineassociated bacteremia). These surveillance data are used primarily to guide control activities, to plan educational programs, and to detect epidemics, but surveillance also may detect infections that require therapeutic action.

Process measures (eg, surveillance of infection control practices) should also be part of the infection control and quality improvement programs and may be very helpful in identifying areas for improvement in practice and for monitoring compliance with regulatory aspects of the infection control program.
Examples of process measures include observation of hand hygiene compliance, observation of correct catheter care technique, antibiotic utilization studies, timeliness in administering and reading TB skin tests, and administration of hepatitis B immunization to new employees within 10 working days of hire.

Using surveillance definitions. Surveillance requires objective, valid definitions of infections. Most hospital surveillance definitions are based on the National Nosocomial Infections Surveillance System (NNIS) criteria, ${ }^{180}$ but no such standard exists for long-term care. NNIS (now the National Healthcare Safety Network [NHSN]) definitions depend heavily on laboratory data and recorded clinical observations. In the LTCF, radiology and microbiology data are less available, and written physician notes and nursing assessments in the medical record usually are brief. Timely detection of HAI in the LTCF often depends on recognition of clues to infection by nurses' aides and reporting of these findings to the licensed nursing staff. ${ }^{181}$ Positive cultures do not necessarily signify infection.

Modified LTCF-specific surveillance criteria were developed by a Canadian consensus conference. These definitions were designed in light of some of the unique limitations of nursing home surveillance mentioned previously. They are used widely, although they have not yet been validated in the field. ${ }^{23}$

Collecting surveillance data. Published LTCF surveys have been either incidence or prevalence studies. Prevalence studies detect the number of existing (old and new) cases in a population at a given time, whereas incidence studies find new cases during a defined time period. The latter is preferred because more concurrent information can be collected by an incidence study if data are collected with regularity.

The surveillance process consists of collecting data on individual cases and determining whether or not a HAI is present by comparing collected data to standard written definitions (criteria) of infections. One recommended data collection method in the LTCF is "walking rounds." 182 This is a means of collecting concurrent and prospective infection data that are necessary to make infection control decisions. Surveillance should be done on a timely basis, probably at least weekly. ${ }^{183}$ During rounds, the ICP may use house reports from nursing staff, chart reviews, laboratory or radiology reports, treatment reviews, antibiotic usage data, and clinical observations as sources of information.

Analysis and reporting of surveillance data. Analysis of absolute numbers of infections is misleading; calculation of rates provides the most accurate information. Rates are generally calculated by using 1000 resident-days as the denominator. In the past, average 
daily census has sometimes been used as the denominator, but resident-days more clearly reflect resident risk.

Infection control data, including rates, then need to be displayed and distributed to appropriate committees and personnel (including administration) and used in planning infection control efforts. The data should lead to specific interventions such as education and control programs.

To compare rates within a facility or to other facilities, the method of calculation must be identical (including the denominator). Even when calculation methods are consistent, infection rates may differ between facilities because of different definitions of infection or differences in resident risk factors and disease severity, and thus comparisons may not be valid. Comparison of infection rates between facilities, for public reporting or other purposes, requires control of definitions and collection methods, severity adjusting and data validation. ${ }^{184}$ The use of a regional data set may allow for more meaningful intrafacility comparison of infection rates. ${ }^{185}$ This may also allow for interfacility comparisons of infection rates across a corporation or geographic area. ${ }^{18}$

Analysis and reporting of infection data usually are done monthly, quarterly, and annually to detect trends. This process is facilitated by an individual infection report form, samples of which have been published. ${ }^{36,186,187}$ The statistics used in analysis of data need not be complex. Computerization for sorting and analysis of data may be timesaving for larger programs, and software for use on a personal computer is available. Graphs and charts facilitate presentation and understanding of infection control data and also may be facilitated by computer programs. The commercially available programs may help with analysis of surveillance data, but manual data collection is still usually necessary.

The feasibility of routine surveillance in LTCFs has been demonstrated, and data have been used to provide a basis for continuing education. ${ }^{188}$ Surveillance needs to be simple and pragmatic, particularly because the LTCF ICP may be able to spend only a few hours per week on infection control activities. ${ }^{181}$

\section{Outbreak control}

Outbreak surveillance and control should be considered a high priority for ICPs. The leading causes of LTCF outbreaks are discussed above and listed in Table 1. When the number of cases exceeds the normal baseline, an outbreak within the facility should be considered. The ICP is advised, and required by CMS, to monitor resident and staff illnesses, since healthy personnel may acquire and transmit virulent pathogens.

For many, the word outbreak means a dramatic clustering of cases of an infectious disease in a geographic area over a relatively short period of time. However, the threshold for declaring an outbreak and initiating control measures may be much lower. For example, we know that influenza may cause explosive outbreaks in nursing homes. ${ }^{59}$ Public health officials have, therefore, set low thresholds for identifying an outbreak if influenza is suspected so that outbreak control strategies can be implemented to avoid high attack rates. The CDC recommends defining a nursing home outbreak of influenza as a single laboratory-confirmed case or a sudden increase of acute febrile respiratory illness over the normal background rate. ${ }^{189}$ Special outbreak control measures may, therefore, be appropriate if there is evidence of transmission of an epidemiologically important pathogen within the facility rather than waiting for a fully evolved clinical outbreak.

For $\mathrm{TB}$, an outbreak investigation should be triggered by a single active case. TB outbreaks are often caused by a single case and may infect large numbers of residents and staff by the airborne route before detection. ${ }^{74,190}$ In addition, a single infection caused by Legionella spp, scabies, Salmonella spp, or other GI pathogens associated with outbreaks should trigger an evaluation. A single case of Legionella spp may signal colonization of the water supply. ${ }^{123}$

The approach to investigating an outbreak includes (1) determining that an outbreak has occurred, (2) developing a case definition, (3) case finding, (4) analyzing the outbreak, (5) formulating a hypothesis regarding mechanism of transmission, (6) designating control measures, and (7) evaluating control measures. A CDC SHEA publication is available to guide investigation of outbreaks. ${ }^{191}$

Given the fact that influenza and norovirus outbreaks are relatively common, clinical case definitions should be developed in advance and placed in preexisting policies and procedures. To facilitate rapid implementation of control measures, the charge nurses should be empowered by preexisting policies to rapidly isolate and/or cohort infected individuals and to curtail contact between residents and staff on units in an outbreak situation.

The LTCF may have difficulty responding to an epidemic with appropriate measures (such as mass vaccination or administration of antivirals during an influenza outbreak) if consent needs to be obtained on short notice from a resident's decision maker or primary physician. One way to circumvent this problem is to develop preexisting policies and procedures approved by the medical staff and to obtain consent for vaccination and outbreak control measures at the time of admission from the resident or their power of attorney/medical decision maker. 


\section{Isolation and precautions: Importance and evolution}

Prevention of transmission of significant pathogens to patients and HCWs is the major goal of isolation within health care systems. There are very limited data on the impact of isolation and infection control precautions, however, on the transmission of pathogens within LTCFs. The high prevalence of risk factors for infection among LTCF residents, the high colonization rate of MDROs in skilled care units, and the frequent reports of LTCF infectious disease outbreaks support the need for appropriate infection control in that setting. ${ }^{136}$ A unique infection control challenge for the LTCF is the mobile resident, who may be confused or incontinent and serves as a possible vector for infectious diseases. ${ }^{7}$

The presence of MDROs in the LTCF has implications beyond the individual facility. Because residents of LTCFs are hospitalized frequently, they can transfer pathogens between LTCFs and receiving hospitals; transfer of patients colonized with MDROs between hospitals and LTCFs has been well documented. ${ }^{192,193}$ On the other hand, LTCF residents remain in the facility for extended periods of time, and the LTCF is functionally their home. An atmosphere of community is fostered, and residents share common eating and living areas and participate in various activities. Thus, the psychosocial consequences of isolation measures must be carefully balanced against the infection control benefits.

Isolation recommendations from the $\mathrm{CDC}$ have been available since 1970 but have specifically been targeted towards acute care settings. ICPs in the LTCF have thus been required to adapt these practices to their individual settings. Traditionally, 2 types of systems for implementing barrier precautions in the hospital were promoted. A Category-Specific System listed 7 categories of isolation or precautions based on means of disease transmission: strict isolation, contact isolation, respiratory isolation, TB isolation, enteric precautions, drainage and secretion precautions, and blood and body fluid precautions. Modifications of this approach have been promoted since 1970 with a refined Category-Specific System in the 1983 recommendations. ${ }^{194,195}$ A Disease-Specific System listed all relevant contagious diseases and the recommended barrier method. In general, the Category-Specific System was simpler to use, but the Disease-Specific System consumed fewer resources because precautions were tailored to the specific disease. In the 1983 guideline, blood precautions were expanded to include body fluids. ${ }^{195}$ In response to the HIV/AIDS epidemic, the concept of Universal Precautions was introduced to protect HCWs from all bloodborne exposures. ${ }^{196,197}$
These recommendations became adopted by OSHA and have thus been applicable to all health care settings including LTCFs. ${ }^{163,198}$ In this system, all blood and certain body fluids are considered potentially infectious. Education, provision of needle-disposal units, provision of protective equipment (such as gloves, gowns, and protective eye wear), and monitoring compliance were part of Universal Precautions, although it alone was not considered a complete isolation system.

CDC isolation guidelines released in 1996 integrated earlier isolation systems by introducing transmissionbased precautions. ${ }^{199}$ Standard Precautions replaced Universal Precautions and were to be applied to all patients. Standard Precautions emphasize hand hygiene, gloves (when touching body fluids), masks, eye protection, and gowns (when contamination of clothing is likely), as well as avoidance of needlestick and other sharps injuries. More specific isolation was recommended for patients with documented or suspected contagious pathogens. These include Airborne Precautions (eg, for varicella, measles, and TB), Droplet Precautions (eg, for influenza and other respiratory infections), and Contact Precautions (eg, for MRSA,VRE, and $C$ difficile diarrhea).

CDC and HICPAC have recently released 2 infection control guidelines that have application in this regard to LTCFs. The first one released focuses specifically on the management of MDROs in health care settings, and the second is an update to previously recommended general isolation precautions from 1996 guidelines. $^{200,201}$ Respiratory hygiene/cough etiquette and safe injection practices were added as new elements of Standard Precautions. Most LTCFs do not have negative-pressure rooms for Airborne Precautions, and residents with suspected TB should be transferred to facilities where such units exist.

\section{Isolation and precautions: MDROs}

The majority of the infection control literature on MDROs in the LTCF has focused on MRSA, but these guidelines may also apply if a facility recognizes significant problems with other MDROs such as VRE or antibiotic-resistant, gram-negative bacilli. Barrier precautions are important in preventing cross infection with known resistant microorganisms, but approaches to isolation of LTCF patients colonized or infected with MDROs vary substantially across facilities. ${ }^{69,156}$

Most LTCFs employ at least some type of isolation for MDROs. ${ }^{202,203}$ It was found that $90.5 \%$ of facilities accepting patients with MRSA stated that they followed Contact Precautions despite only $39.7 \%$ placing them in private rooms. ${ }^{202}$ In another survey, most LTCFs in 
Nebraska were aware of and often screened for MRSA and employed some precautions in dealing with these residents (eg, single room, cohorting, contact isolation, or placing the resident with MDRO in the same room as a low-risk roommate). ${ }^{203}$ Another study demonstrated no difference in transmission of MDROs in a skilled care unit between contact isolation precautions and routine glove use. ${ }^{204}$ The authors suggested that universal glove use may be preferable to contact isolation because it reduces social isolation for LTCF residents where their health care facility is also their home. Others have suggested a "modified" contact isolation protocol as often more appropriate in the LTCF setting. ${ }^{205}$ Clearly, additional evidence-based studies defining the specific isolation needs within LTCF are needed.

General guidelines for control of MRSA ${ }^{148}$ and $\mathrm{VRE}^{206}$ are published but emphasize hospital settings. These guidelines serve as an appropriate starting point for adapting an LTCF approach. There are many reports of aggressive infection control measures containing MDROs in the hospital setting. ${ }^{200}$ However, data in the LTCF are very limited, and implementation of isolation procedures identical to those found in a hospital may result in undesirable social and psychological consequences and functional decline for residents. ${ }^{207}$ SHEA position papers on antimicrobial resistance and infection control specifically address the LTCF $^{208,209}$ and discuss prescreening admissions for resistant bacteria, surveillance for resistant bacteria, and endemic resistance.

The recent HICPAC isolation guidelines attempt to address some of the specific needs and concerns of the LTCF. ${ }^{200,201}$ The principles in both documents can be adopted for use in the LTCF setting. The MDRO document discusses general control interventions such as administrative support, education of HCWs, surveillance, and judicious use of antimicrobial agents (see Antibiotic stewardship section below) that are applicable in the LTCF setting. LTCFs are encouraged to identify experts who can provide consultation for analyzing surveillance data and devising effective infection control strategies to control MDROs. The development of laboratory protocols for storing bacterial isolates for molecular typing when needed to understand the epidemiology of transmission is recommended. When the LTCF laboratory has contracted with an off-site laboratory, the facility will need to develop an arrangement for storing and testing isolates.

The guidelines ${ }^{200,201}$ recommend continuing the use of transmission-based isolation precautions. In LTCFs, it is advised to consider the individual resident's clinical situation when deciding whether to implement or modify the use of Contact Precautions in addition to Standard Precautions if colonized or infected with a
MDRO. Standard Precautions are sufficient for relatively healthy and independent residents, ensuring that gloves and gowns are used for contact with uncontrolled secretions, pressure ulcers, draining wounds, stool, and ostomy tubes/bags.

Contact Precautions are indicated for residents with MDROs who are ill and totally dependent upon HCWs for activities of daily living or whose secretions or drainage cannot be contained. Single rooms for these residents are recommended if available. The cohorting of MDRO residents is acceptable if single rooms are not available. If cohorting is not possible, then placing residents with MDRO with residents who are low risk for acquisition or with anticipated short lengths of stay is advised. While "low risk for acquisition" of an MDRO has not been officially defined, one source suggested that it should include residents who are not immunosuppressed; not on antibiotics; and free of open wounds, drains, and indwelling urinary catheters. $^{209}$ Case-by-case decisions, as needed, can be made regarding the best precautions to use for each resident with a MDRO. With Contact Precautions, wearing a gown and gloves for all interactions that may involve contact with the resident and their environment is advised, and eye protection is recommended when there is risk of splash or spray of respiratory or other body fluids.

Recommendations for minimizing antibiotic resistance also include using appropriate barrier precautions for MDROs, maintaining a line listing of residents infected or colonized with MDROs, and not attempting eradication of MDROs from colonized residents. ${ }^{208}$ It is not recommended that the LTCF refuse MRSA or VRE cases but develop an institutional strategy for control of the resistant organisms based on local considerations. ${ }^{133,148,208,210}$

In summary, elements of routine MDRO control for the LTCF include monitoring MRSA and VRE culture results, communicating MDRO data to health care providers, including routine communication about MDROs at in-services, assessing compliance with isolation precautions and hand hygiene, monitoring antimicrobial usage, notifying receiving or transmitting facilities of the presence of a MDRO, designating residents previously known to be infected or colonized with MDROs, and instituting adequate environmental cleaning. If a MDRO problem exists in a LTCF and is not controlled with these basic infection control practices, then additional control measures are indicated. These include consultation from experts, intensification of education, increased efforts to control antimicrobial use, active surveillance cultures, pointprevalence culturing of targeted units, intensification of isolation with compliance assessment, and monitoring environmental cleaning. 


\section{Isolation and precautions: Bloodborne pathogen issues}

LTCFs may be asked to provide care for persons with hepatitis $\mathrm{C}$, hepatitis B, HIV, and acquired immunodeficiency syndrome (AIDS), especially for individuals with advanced disease who are too ill to reside at home but do not require acute hospital care. Earlier guidelines for dealing with HIV infection in the health care setting are incorporated widely in hospitals but also apply in the LTCF. $^{197,199}$ The standard approaches to protecting HCWs and other patients from transmission of bloodborne pathogens have essentially not changed since these earlier recommendations. In the current isolation guidelines, ${ }^{201}$ Standard Precautions are still promoted as the main method for preventing exposure to blood and body fluids for all patient interactions. These include the routine use of hand hygiene, gloves, gowns, masks, and eye protection, depending upon the anticipated exposures.

The guideline also discusses in detail safe work practices to prevent exposures to bloodborne pathogens, including prevention of needlesticks and other sharp-related injuries; prevention of mucous membrane contact; safe injection practices; and precautions during aerosol-generating procedures. Infection control personnel at all LTCFs should carefully review these guidelines and develop a plan for implementation within their facilities. As in hospitals, it is known that needlestick injuries do occur in the LTCF and usually are related to needle recapping. ${ }^{211}$ Plans for regular education of all staff and for compliance with OSHA standards should be in place, and LTCFs should ensure the availability to hepatitis B vaccination and postexposure prophylaxis for HIV or hepatitis B for all employees in accordance with the most recent guidelines. ${ }^{212}$

\section{Hand hygiene}

Hand hygiene likely remains the most important infection control measure in the LTCF as well as in the hospital. Unfortunately, poor compliance with hand hygiene recommendations has been noted in LTCFs, as in other settings. ${ }^{213,214}$ Health care provider hand contamination is usually transient and amenable to hand hygiene, ${ }^{215}$ frequent hand hygiene would be expected to lower LTCF infection rates, ${ }^{203,216}$ and the availability of alcohol-based hand sanitizer dispensers enhances access to hand sanitizing agents.

CDC and HICPAC published a comprehensive hand hygiene guideline. ${ }^{217}$ Other published guidelines for hand hygiene and choice of antiseptic agents are also applicable. ${ }^{218,219}$ They recommend the use of bar or liquid soap when hands are visibly dirty or contaminated with proteinaceous material or visibly soiled with blood or other body fluids. If hands are not visibly soiled, then the routine use of an alcohol-based hand rub is recommended in the LTCF. Hands should always be decontaminated after the removal of gloves. Hand hygiene with an antiseptic agent or alcohol-based hand rub is recommended before donning sterile gloves for performing invasive procedures such as placement of an intravenous or urinary catheter. Hand hygiene compliance should be monitored by the facility.

\section{Resident health}

Resident health programs are recommended for prevention of infections, ${ }^{7}$ but comprehensive programs often are lacking in LTCFs. ${ }^{149}$ One of the major functions of a resident health program is the immunization of the elderly resident. ${ }^{59,220,221}$ The elderly are underserved in terms of immunization to tetanus, ${ }^{222}$ as well as pneumococcal and influenza vaccines. ${ }^{223}$ They should receive pneumococcal vaccine at age 65 , when they are relatively immunologically responsive, rather than at age 80 to 85 when entering the LTCF. ${ }^{57}$ Standing orders for influenza and pneumococcal vaccination are associated with improved vaccination rates. ${ }^{224}$ Residents should receive a TB skin test on admission and undergo chest radiograph if TST positive or symptomatic. ${ }^{78}$

Other resident care practices that should be addressed include resident hand hygiene, oral hygiene, prevention of aspiration, skin care, and prevention of UTIs. Clinical trials in LTCFs have reported no decrease in infections with routine vitamin or mineral supplementation. ${ }^{225,226}$ However, optimal care of comorbid illnesses and good nutrition are principles of care irrespective of impact on infections.

\section{Employee health}

Published information on infection control in hospital personnel is available. ${ }^{227-229}$ Employee infection prevention considerations in the LTCF are somewhat different than in the hospital, but the published literature and guidelines generally apply to the LTCFs as well as hospitals. Because of congregate living conditions in most LTCFs, there are some notable differences including an increased risk of exposure to residents with herpes zoster, scabies, conjunctivitis, influenza, TB, and viral gastroenteritis. The pediatric LTCF offers additional challenges to the prevention of infection including childhood diseases, such as varicella, measles, mumps, and rubella.

Regulations concerning protection of employees from bloodborne pathogens apply to the LTCF. ${ }^{163,196}$ The LTCF should be able to provide timely chemoprophylaxis to employees who may have blood/body fluid exposure to residents known to have $\mathrm{HIV}^{212}$ 
Employee health policies and procedures should address postexposure follow-up or prophylaxis for certain infections, such as hepatitis B, hepatitis C, TB, scabies, and HIV.

Primary employee vaccination considerations should include influenza, hepatitis B, tetanus/diphtheria, and pertussis. Varicella, measles, mumps, rubella, and hepatitis A are of greater concern in the pediatric LTCF setting. Influenza vaccine campaigns should require signed declination statements by employees who decline vaccination. ${ }^{230}$

Adult vaccination information can be found at http:// www.immunize.org/. Vaccination should include hepatitis B to protect from this bloodborne pathogen. Varicella vaccine is appropriate if an employee is not immune. Hepatitis A vaccine may be appropriate in certain circumstances, especially in behavioral health and developmental disability facilities. Vaccine Information Sheets (VIS) should be given to all adult vaccinees as required by the National Childhood Vaccine Injury Act (42 U.S.C. §300aa-26). Anaphylaxis or any other adverse event requiring medical attention within 30 days after receipt of a vaccine must be reported to the Vaccine Adverse Events Reporting System (VAERS), a requirement of the National Vaccine Injury Compensation Program (www.vaers.org/pdf/vaers_form.pdf).

Initial assessment of employees and education in infection control also are important, as is a reasonable sick-leave policy. ${ }^{150}$ Ill employees may cause significant outbreaks in the LTCF. ${ }^{124}$ Initial screening should include TB, also required by some states. ${ }^{231,232}$ LTCFs are required to prohibit employees with communicable diseases or infected skin lesions from direct contact with residents and to prohibit employees with potentially infectious skin lesions from contact with residents' food. ${ }^{159}$

Education. The value of education of the LTCF ICP has long been recognized, and surveys of personnel confirm this need. ${ }^{233}$ The importance of ICP education is accentuated by the great turnover in LTCF personnel. While the benefits of ICP training are widely assumed, one study analyzed the effects of a 2-day, intensive basic training program on 266 ICPs. ${ }^{234,235}$ Trainees not only demonstrated an increase in postcourse knowledge but, at 3- and 12-month follow-up, had a significant increase in implementation of key infection control practices. Practices included performance of surveillance, using infection definitions, calculating infection rates, and giving employees and residents TST and influenza vaccine.

The role of education in infection prevention in the LTCF extends well beyond the ICP. One of the most important roles of the ICP is education of LTCF personnel in basic infection control principles. It is recommended that the ICP routinely assess the educational needs of staff, residents, and families and develop educational objectives and strategies to meet those needs; collaborate in the development, delivery, and evaluation of educational programs or tools that relate to infection prevention, control, and epidemiology; and continuously evaluate the effectiveness of educational programs and learner outcomes.

Education should focus on new personnel and certified nursing assistants. ${ }^{186}$ Priority for training should be directed toward orientation, OSHA-mandated programs, problem-oriented teaching, and other programs required by regulations. Surveillance data are an excellent starting point for infection control training, and compliance rounds provide an opportunity for the ICP to provide timely, informal education to personnel. Infection control content should include information on disease transmission, hand hygiene, barrier precautions, and basic hygiene. ${ }^{234}$ In addition, all individuals with direct resident care responsibility need education in early problem and symptom recognition. The teaching methods used need to be sensitive to language, cultural background, and educational level. A coordinated, effective educational program will result in improved infection control activities. ${ }^{235}$

\section{Antibiotic stewardship}

Antibiotic-resistant bacteria pose a significant hazard in the LTCF, and this resistance has been strongly associated with antibiotic use. ${ }^{136,236-240}$ Antimicrobials are among the most frequently prescribed medications in the LTCF. ${ }^{241}$

Antibiotics are given to approximately $7 \%$ to $10 \%$ of residents in LTCFs, frequently for lengthy periods of time. ${ }^{242-244}$ A study of 22 LTCFs noted an incidence of antibiotic prescriptions of 2.9 to 13.9 antibiotic courses per 1000 resident-days. ${ }^{245}$ Several studies have questioned the appropriateness of this practice. ${ }^{242-244}$ A common problem is the failure to distinguish infection and colonization (such as a positive swab culture of a pressure ulcer or a urine culture showing bacteriuria without signs or symptoms of infection) and the treatment of the colonization with antibiotics. In addition, antibiotics often are prescribed over the telephone in this setting. ${ }^{246}$ There also appears to be significant variability in antibiotic prescribing patterns in the LTCF. ${ }^{247}$

Several reviews and guidelines for infection control efforts to curb antibiotic resistance in health care settings (including LTCFs) have been published. ${ }^{167,173,200}$ These guidelines stress the importance of having an ICP trained in infection control and LTCF administrative support and resources for the infection control program. ${ }^{237}$ The $\mathrm{CDC}$ has published a 12-step program for preventing antimicrobial resistance among LTCF 
residents that addresses the broad areas of preventing infection (eg, resident vaccination), diagnosis/treatment of infection, using antibiotics wisely, and preventing transmission (www.cdc.gov). A LTCF antibiotic review program is recommended ${ }^{173}$ and is often found in LTCFs. ${ }^{248,249}$

Recent guidelines have addressed the development of antimicrobial stewardship programs in hospitals. ${ }^{250}$ Using this guideline as a starting point, LTCFs are encouraged to include antimicrobial stewardship in the LTCF infection control program and discuss appropriate choices for various clinical situations. ${ }^{241}$ A recent survey revealed that fewer than one third of LTCFs surveyed had any such antibiotic use protocols in place. ${ }^{251}$ Minimum criteria for initiation of antibiotic therapy have been proposed to improve antimicrobial prescribing in LTCFs $^{252}$ and may be of assistance in developing antibiotic appropriateness criteria.

Approximately two thirds of LTCF professionals identified a clear need for greater education regarding judicious antibiotic use in LTCFs. ${ }^{251}$ Education and development of antibiotic guidelines have improved antimicrobial usage in the LTCF setting in several studies. $^{253,254}$

\section{Other aspects of the program}

Policies and procedures. An important aspect of infection control programs is the development and updating of infection control policies and procedures. Because practices change, they should be reviewed on a scheduled basis. Review of the Bloodborne Pathogens Exposure Control Plan is required to be done annually. ${ }^{163}$

Resources are available on the writing of policies and procedures in general ${ }^{255,256}$ dietetic service policies, ${ }^{255}$ laundry policies, ${ }^{257}$ physical therapy policies, ${ }^{255,258,259}$ and handwashing. ${ }^{217-219}$ Respiratory therapy issues may be relevant to the LTCF, including cleaning of humidifiers, respiratory therapy equipment, suctioning technique, and tracheotomy care. ${ }^{36}$ Pharmacy and medication issues include use of multidose medication vials and resident specific creams and ointments.

A policy and procedure on hand hygiene are critically important to have available for staff. ${ }^{217}$ The policy details specific indications for hand hygiene, including when coming on duty; whenever hands are soiled; after personal use of toilet; after blowing or wiping nose; after contact with resident blood or body secretions; before performing any invasive procedures on a resident; after leaving an isolation room; after handling items such as dressings, bedpans, catheters, or urinals; after removing gloves; before eating; and on completion of duty. The corresponding procedure should list explicit steps in the hand hygiene process. A 15-second handwash is usually recommended. ${ }^{36,219}$ Alcohol-based hand rubs should be made available and used by staff, especially when handwashing facilities are inadequate or inaccessible. Hand hygiene compliance should be monitored. ${ }^{217}$

Facility management. Environmental control in the facility is an important consideration. Routine environmental cultures are not cost-effective and do not usually generate information relevant to clinical infections. However, periodic environmental compliance rounds are recommended. ${ }^{186,258}$ Sources are available suggesting specific environmental measures such as dishwasher and laundry cleaning temperatures, ${ }^{186,258,260}$ although limited data exist.

A related area of concern is sterilization, disinfection, and asepsis, including the evaluation of cleaning methods, such as monitoring reuse of disposable equipment. Resources are available. ${ }^{261,262}$ An infection control program should also monitor basic hygiene (eg, respiratory etiquette) and compliance with proper infection control techniques. Staff, residents, and families may all be the source of HAIs if there is a breakdown in basic hygiene.

Selection of proper disinfectants and antiseptics requires infection control expertise. Reading the manufacturer's label directions and following the required dilution and contact time instructions are recommended. Infection control input will also be needed on additional and new products that affect infection prevention, such as urinary catheter systems, gloves, and disposable diapers. Quality, efficacy, and cost issues need to be weighed in product selection. ${ }^{263}$

Waste management is the important in the LTCF. Medical and biohazardous waste issues are controversial; Environmental Protection Agency (EPA) regulations, OSHA regulations, and CDC recommendations may conflict. ${ }^{264}$ Local health department regulations should also be checked. Several resources are available on medical waste issues relevant to the LTCF. ${ }^{162,255,258,260,264,265}$

Disease reporting. Another important function of the infection control program is disease reporting to public health authorities. State and local health departments will provide a list of reportable diseases and other public health resources.

Performance improvement/resident safety. The increased emphasis on quality indicators in health care is becoming evident in LTC. There are important differences in definitions of infection published for LTCF surveillance (see Surveillance section above) and those in the long-term care Minimum Data Set (MDS) manual. This is especially important for UTIs. In addition, CMS provides a Web site called Nursing Home 
Compare, ${ }^{58}$ which posts information to the public on nursing home quality measures, inspections, staffing, and other data for individual LTCFs. For instance, UTI in the CMS MDS requires a physician diagnosis in the chart and a positive urine culture. ${ }^{266}$ This definition has been found to be inaccurate compared with standard definitions such as the McGeer definition, ${ }^{23}$ which requires a combination of symptoms and signs. ${ }^{267}$

A quality assessment and assurance committee is required. ${ }^{159}$ Infection control is the prototype quality improvement or performance improvement (PI) program, and many of the techniques used in infection control are directly applicable to PI, such as data collection, data analysis, and intervention. ${ }^{268,269}$ The traditional performance improvement process focuses on adverse events and assesses functions of the system. ${ }^{270,271}$ In the course of performing infection surveillance, there is ample opportunity to monitor compliance with infection control policies and procedures and to provide informal infection control education to address observed problems.

Examples of appropriate quality indicators for PI study include resident immunization with influenza and pneumoccoccal vaccines, ${ }^{272}$ employee vaccination for influenza, ${ }^{273}$ number of employee TST conversions, and employee hand hygiene compliance. A national focus on patient safety and prevention of adverse events has relevance to the LTC setting as well. ${ }^{274}$

Preparedness planning. The ICP will frequently play a key role in LTCF preparedness planning. The planning is currently focused on pandemic influenza but should prepare the LTCF for dealing with a variety of disaster scenarios. Issues to be considered include surge capacity, medication availability and rationing, stockpiling, staff shortages during an influenza pandemic, and communication with public health authorities for planning purposes. ${ }^{275,276}$ It appears that the LTCF ICP will play an important role in preparedness and that about half of LTCFs have a pandemic influenza plan. $^{277}$

\section{RESOURCES}

Having appropriate job-related resources is essential to good performance in the role of infection prevention and control. A few resources for the ICP are listed below:

1 Smith PW, editor. Infection control in long-term care facilities. 2nd ed. Albany, NY: Delmar Publishers, Inc (800-347-7707); 1994. Cost, \$38.95.

2 APIC infection connection: long-term care facilities newsletter. Available from the Association for Professionals in Infection Control and Epidemiology (202296-2742). Cost for nonmembers, \$15.
3 Strausbaugh LJ, Joseph C. Epidemiology and prevention of infections in residents of long-term care facilities. In: Mayhall CG, editor. Hospital epidemiology and infection control. Baltimore, MD: Williams \& Wilkins (800-6380672); 2004. Cost, \$199.

4 Heymann DL, editor. Control of communicable diseases manual. 18th ed. Washington, DC: American Public Health Association; 2004. Cost, \$33.00.

5 Horan-Murphy E, Barnard B, Chenoweth C, Friedman C, Hazuka B, Russell B, et al. APIC/CHICACanada infection control and epidemiology: professional and practice standards. Am J Infect Control 1999;27:47-51.

6 McGeer A, et al. Definitions of infection for surveillance in long-term care facilities. Am J Infect Control 1991;19:1-7.

7 APIC text of infection control and epidemiology. Washington, DC: Association for Professionals in Infection Control and Epidemiology, Inc.; 2005.

8 Nicolle LE, Garibaldi RA. Infection control in longterm care facilities. Infect Control Hosp Epidemiol 1995;16:348-53.

\section{RECOMMENDATIONS}

See Table 4 for scoring scheme.

\section{A. Infection control program}

1 An active, effective, facility-wide infection control program should be established in the LTCF. The purpose of the program is to help prevent the development and spread of infectious diseases (Category IC).

Comment: The elements of a program generally include the following:

a. Surveillance-Systematic data collection to identify infections in residents

b. Outbreak Control-A system for detection, investigation, and control of epidemic infectious diseases in the LTCF

C. Isolation-An isolation and precautions system to reduce the risk of transmission of infectious agents d. Policies and procedures-Relevant to infection control (see Table 2)

e. Education-Continuing education in infection prevention and control

f. Resident health program

g. Employee health program

h. Antibiotic stewardship-A system for antibiotic review and control

i. Disease reporting to public health authorities

j. Facility management, including environmental control, waste management, product evaluation and disinfection, sterilization and asepsis 


\section{Table 4. Categorization of recommendations}

In this document, as in a number of published HICPAC, SHEA, and APIC guidelines, each recommendation is categorized on the basis of existing scientific evidence, theoretical rationale, applicability, and national or state regulations. The following categorization scheme is applied in this guideline:

Category IA. Strongly recommended for implementation and strongly supported by well-designed experimental, clinical, or epidemiologic studies.

Category IB. Strongly recommended for implementation and supported by some experimental,clinical, or epidemiologic studies and by strong theoretical rationale.

Category IC. Required for implementation, as mandated by federal or state regulation or standard.

Category II. Recommended for implementation and supported by suggestive clinical or epidemiologic studies or by theoretical rationale. No Recommendation. Unresolved issue. Practices for which insufficient evidence or no consensus regarding efficacy exists.

k. Performance improvement/resident safety

1. Preparedness planning

2 The infection control program must be in compliance with federal, state, and local regulations (Category IC).

\section{B. Infection control administrative structure}

1 Oversight of the infection control program should be defined and should include participation of the ICP, administration, nursing staff, and physician staff (Category II).

Comment: A committee, traditionally the ICC (infection control committee), may oversee the infection control program for the facility. ICC members often include the ICP; the medical director; and representatives from nursing, administration, and pharmacy. Participation of other departments, such as dietary, housekeeping, and physical therapy, should be considered on an ad hoc basis. Administrative structures other than an ICC may provide oversight to the infection control program. One example is an infection control oversight committee, a small group consisting of the LTCF administrator, the ICP, and the medical director. Alternatively, the performance improvement committee or patient safety committee and the ICC may be combined, but it is important to maintain the identity of the infection control program. The duties of the ICC should be delegated appropriately if no formal ICC exists.

2 Formal delegation of infection control oversight should be made in writing (Category II).

3 The infection control oversight committee should meet on a regular basis and have a mechanism for emergent meetings as needed (Category II).
4 This committee should maintain written minutes with identification of problems and plans for action (Category II).

5 The effectiveness of the infection control program should be evaluated by the administration on at least an annual basis (Category II).

6 Policies and procedures for investigating, controlling, and preventing infection transmission in the facility should be established (Category IC).

Comment: Other functions include (a) review of infection control data, (b) approval of policies and procedures, (c) monitoring program activities, and (d) recommending policy to the facility administration.

7 Consultation should be available as needed including with an infectious disease physician or other professional with expertise in infection control (Category II).

\section{ICP}

1 One person, the ICP, should be assigned the responsibility of directing infection control activities in the LTCF. The ICP should be someone familiar with LTCF resident care problems (Category IC).

2 The ICP should have a written job description of infection control duties (Category II).

3 The ICP is responsible for implementing, monitoring, and evaluating the infection control program for the LTCF (Category II).

4 The ICP should be guaranteed sufficient time and the support of the administration to effectively direct the infection control program (Category II).

5 The ICP (or another appropriate individual, such as the medical director) should have written authority to institute infection control measures in emergency situations (Category IB).

6 The ICP should have a sufficient infection control knowledge base to carry out responsibilities appropriately (Category II).

Comment: A background in infectious diseases, microbiology, geriatrics, and educational methods is advisable. Management and teaching skills also are helpful. Continuing education is essential for the ICP (eg, meetings, courses, journals).

7 The ICP should know the federal, state, and local regulations dealing with infection control in the LTCF (Category II).

8 The ICP should communicate with relevant facility committees and personnel within the facility, ICPs from transferring facilities, and public health authorities to ensure appropriate isolation and collection of surveillance information (Category II). 
9 No recommendation on number of ICPs per $100 \mathrm{LTCF}$ beds.

\section{Surveillance}

1 The LTCF should have a system for ongoing collection of data on infections in the institution (Category IC).

2 A documented surveillance procedure should be used, including written definitions of infections (Category IB).

Comment: Concurrent surveillance is preferable to retrospective surveillance. The frequency of surveillance for HAIs in the LTCF should be based on factors such as acuity level of the resident population. Surveillance at least once a week generally is needed to collect timely data. Surveillance data should be collected from communication with staff; this may be during walking rounds in the LTCF. Medical progress notes in the chart, laboratory or radiology reports, nursing notes, treatment records, medication records, physical assessments, environmental observations, and follow-up information from transfers to acute care hospitals provide clues to the presence of infections.

3 The ICP should review surveillance data frequently and recommend infection control measures, as appropriate, in response to identified problems (Category IB).

Comment: Analysis of surveillance data should include at least the following elements on each infection to detect clusters and trends: resident identifier, type of infection, date of onset, location in the facility, and appropriate laboratory information.

4 Infection rates should be calculated periodically, recorded, analyzed, and reported to the administration and the infection control oversight committee (Category IB).

Comment: Infection rates usually are calculated monthly, quarterly, and annually. HAI rates are calculated preferably as infections per 1000 resident-days. A standard infection report form facilitates reporting of surveillance information. Tables, graphs, and charts may be used and facilitate education of personnel.

5 Surveillance data should be used for planning infection control efforts, detecting epidemics, directing continuing education, and identifying individual resident problems for intervention (Category IB).
Comment: In addition to collection of baseline infection rates, the ICP should perform problemfocused studies. Examples of special studies are evaluation of UTIs in catheterized residents, a study of the occurrence of influenza in vaccinated versus unvaccinated residents, or the prevalence of pressure ulcers in bed-bound residents.

6 In addition to the above outcome measures, surveillance should also include analysis of process measures relevant to infection control (Category II).

Comment: Examples include monitoring hand hygiene compliance, observation of aseptic technique, and measuring $\mathrm{HCW}$ influenza vaccination rates.

\section{E. Outbreak control}

1 Surveillance data should be used to detect and prevent outbreaks in the LTCF (Category IB/IC).

Comment: The occurrence of even a single verified case of a highly transmissible disease (such as infectious TB, influenza, scabies, Salmonella, and norovirus) in the LTCF should prompt notification of appropriate individuals (such as the medical director or administrator), consideration of an outbreak, and institution of control measures. After the institution of isolation precautions, assessment of exposed residents and personnel should be made in a timely fashion to detect other cases.

2 The facility should define authority for intervention during an outbreak (Category IB).

Comment: The LTCF should have a preexisting protocol for dealing with infectious disease epidemics, including the authority to relocate residents, confine residents to their rooms, restrict visitors, obtain cultures, isolate, and administer relevant prophylaxis or treatment (such as antivirals during an influenza outbreak).

3 In order to facilitate response to an outbreak, consent for appropriate diagnostic or therapeutic measures should be obtained from the resident or medical decision maker and the resident's primary physician on admission to the facility (Category II).

4 Obtaining cultures of the environment or from asymptomatic personnel is not recommended except as targeted by an epidemiologic investigation (Category II).

5 A TB control program should focus on detection of active cases in residents and staff and isolation or transfer of residents with known or suspected pulmonary TB disease (Category IC). 
Comment: TB control programs are mandated by OSHA. A case of TB in residents or staff that was or may have been acquired in the facility should lead to clinical evaluation and TB testing of residents and employees.

\section{F. The facility}

1 Hand hygiene facilities and supplies should be available and conveniently located for residents and staff (Category IA).

2 Clean and soiled utility areas should be functionally separate and clearly designated (Category IC).

3 Appropriate ventilation and air filtration should be addressed by the LTCF (Category IC).

Comment: If the LTCF provides care for residents or accepts residents with a diagnosis of active $\mathrm{TB}$, the airborne infection isolation (AII) requirement should be met. If these requirements cannot be met, a system for transfer of cases to an appropriate institution that provides AII should be part of the overall infection control plan.

4 Housekeeping in the facility should be performed on a routine and consistent basis to provide for a safe and sanitary environment (Category IC).

Comment: Cleaning schedules should be kept for all areas in the LTCF. Cleaning products should be approved and labeled appropriately; manufacturer's (or other authoritative) recommendations for use and dilution should be followed.

5 Measures should be instituted to correct unsafe and unsanitary practices (Category II).

Comment: Environmental cleanliness may be monitored by walking rounds with a checklist for each area of the LTCF. Nursing interventions may be monitored by direct observation during such rounds.

6 Areas in the LTCF with unique infection control concerns (eg, laundry, kitchen, rehabilitation) should have the appropriate policies and procedures developed (Category II).

Comment: Laundry policies and procedures should address the following: proper bagging of linen at the site of use, transporting linen in appropriate carts, cleaning of the carts on a regular basis, separation of clean and soiled linen, washing temperatures or use of an appropriate chemical mix for low-temperature washing, covering of clean linen, protection of personnel handling soiled laundry, and hand hygiene after contact with soiled linen. Adequate supplies of clean linen should be available. Laundry regulations should be addressed if the facility does its own laundry. Dietetic service area policies and procedures should address the following: handling of uncooked foods, cooking of food, cleaning of food preparation areas, food storage, cooking and refrigeration temperatures, cleaning of ice machines, hand hygiene indications, and employee health. Food and drink should be limited to specific areas. Policies and procedures covering infection control aspects of physical therapy (including cleaning of hydrotherapy tanks) should be developed. It should include cleaning and disinfection of hydrotherapy equipment, hand hygiene indications, and cleaning of exercise equipment. If pets are allowed, the LTCF should have a policy defining access, containment, cleanliness, and vaccination of pets.

7 Policies and procedures for disposal of infectious medical waste (including waste categorization, packaging, storage, collection, transport, and disposal) should be developed in accordance with federal, state, and local regulations (Category IC).

Comment: Examples of specific issues include types of waste disposal bags, cleaning of waste transportation carts, and types of waste storage containers. Policies for sharps disposal should be developed.

\section{G. Isolation and precautions}

1 Isolation and precautions policies and procedures should be developed, evaluated, and updated in accordance with most recent CDC/HICPAC guidance (Category IC).

2 Regular education programs should be developed to reinforce understanding and compliance (Category IC).

3 Compliance with these infection control practices (eg, hand hygiene, isolation) should be monitored (Category IC).

4 Any isolation and precautions system used should include implementation of Standard Precautions for all residents (eg, wearing of gloves, masks, eye protection, and gowns when contamination or splashing with blood or body fluids is likely) (Category IC).

5 Any isolation and precautions system should include the implementation of transmission-based precautions (Contact Precautions, Droplet Precautions, or Airborne Precautions) in accordance with current CDC/HICPAC guidance (Category IB/IC).

6 The LTCF should have a policy dealing with MDROs (such as MRSA or VRE) that is compatible with current national standards (such as the HICPAC isolation and MDRO guidelines) and appropriate to the LTCF setting (Category IB). 
Comment: This policy should deal with issues such as acceptance of colonized or infected patients into the facility, inquiring about colonization of admissions with MDROs, and isolation of residents with MDROs. Denial of admission to the LTCF solely on the basis of colonization or infection with a resistant organism is not appropriate. HICPAC recommends intensification of containment measures for MDROs if ongoing transmission is occurring.

7 The individual resident's clinical situation should be considered when deciding whether to implement or modify the use of Contact Precautions in addition to Standard Precautions if colonized or infected with a MDRO (Category IB/IC).

Comment. Routine glove use is an example of a form of modified Contact Precautions, but it has not been validated in the LTCF setting.

8 A program of safe work practices to prevent HCW exposure should be developed in accordance with $\mathrm{CDC} / \mathrm{HICPAC}$ and OSHA guidance. Used needles and syringes should not be manually recapped, broken, or bent. Self-capping needles should be used. They should be disposed of, with all sharps, in a puncture-resistant, leak-proof container (Category IC).

9 Gloves are indicated for contact with blood or body fluids, contaminated items, mucous membranes, or nonintact skin (Category IC).

10 Policies should be developed to deal with spills and personnel exposure to blood or body fluids. Employees should know how to respond to an exposure (eg, immediately washing the skin in the event of a blood exposure). Postexposure prophylaxis should be readily available (Category IC).

11 Residents with suspected TB should be placed in a negative-pressure room or transferred to a facility with such a room (Category IC).

\section{H. Asepsis and hand hygiene}

1 Routine hand hygiene should be encouraged. Hands should be washed after any patient contact but especially after contact with body fluids, after removing gloves, when soiled, and when otherwise indicated (Category IA). Unless hands are visibly soiled, use of alcohol-based hand gels is encouraged (Category IA/IC).

2 A hand hygiene policy and procedure should be developed by the LTCF in accordance with current $\mathrm{CDC} / \mathrm{HICPAC}$ guidance with a program of ongoing hand hygiene education (Category IB/IC).

3 Hand hygiene compliance should be monitored (Category IC).
4 Policies and procedures for disinfection and sterilization should be developed (Category IB).

Comment: These policies and procedures should address issues such as sterile supplies, reuse of disposable items, disinfection of equipment (such as thermometers), and cleaning of noncritical items. All items, other than disposables, should be cleaned, disinfected, or sterilized, following published guidelines and manufacturers' recommendations. The ICP should identify those resident care procedures that require aseptic technique.

\section{Resident care}

1 Resident rooms should have an accessible sink, with soap, water, towels, and toilet facilities (Category II).

Comment: Provision should be made for maintaining adequate resident personal hygiene and for instructing residents in hygiene and hand hygiene as appropriate to their functional status.

2 A resident skin care program should be developed to maintain the skin as a barrier to infection (Category II).

Comment: Resident skin care should include the following: routine frequent turning for those unable to do so themselves, keeping the residents clean and dry, inspecting all residents' skin on a routine basis, ensuring appropriate nutrition, treating pressure ulcers, and providing prompt care for any other breaks in skin integrity. Turning schedules and pressure ulcer assessment forms may be useful.

3 A program to prevent UTIs should be developed, including the following:

- Routine urinalysis or urine culture to screen for bacteriuria or pyuria is not recommended (Category IA).

- Residents with impaired bladder emptying managed with intermittent catheterization should be managed with a clean technique (Category IA).

$\bigcirc$ Policies for catheter use should address catheter insertion, closed drainage systems, maintenance of urinary flow, and indications for changing the catheter (Category IB).

$O$ Irrigation of indwelling catheters with saline or antiseptics is not routinely recommended (Category IB).

- If leg bags are used, the LTCF should develop policies and procedures for aseptic connection, cleaning, and storage of leg bags (Category II).

- Adequate hydration should be maintained (Category II). 
Comment: Men with incontinence should have voiding managed by a condom catheter rather than indwelling catheter, where possible. Residents with chronic indwelling catheters should have the catheter replaced and a specimen collected immediately prior to initiating antimicrobial therapy for symptomatic infection.

4 A program to minimize the risk of pneumonia in the LTCF should address the following: reducing the potential for aspiration, minimizing atelectasis, and caring for respiratory therapy equipment (Category II).

Comment: Pneumonia prevention guidelines are available, and many of the suggested measures are applicable to the LTCF.

5 Policies and procedures should be developed for prevention of infections associated with nasogastric and gastrostomy feeding tubes, including the following: preparation, storage, refrigeration, and administration of feeding solutions and care of percutaneous feeding tube skin sites (Category II).

6 Policies and procedures should be developed for prevention of IV infections, including central lines, if these devices are used (Category IB).

Comment: Policies should address indications for IV therapy, the type of dressing used to cover the IV exit site, cannula insertion, site maintenance, and changing fluids or tubing.

\section{J. Resident health program}

1 A resident health program should be implemented (Category II).

- There should be explicit and accessible documentation of program components in the resident record (Category II).

2 At admission, each resident should have a complete history (including important past and present infectious diseases), immunization status evaluation, and recent physical examination (Category II).

3 All newly admitted residents should receive TB screening unless a physician's statement is obtained that the resident had a past positive TST (Category IA/ IC).

Comment: A 2-step booster TST is often recommended in this setting.

4 When new or active TB is suggested by a positive skin-test result, or symptoms are consistent with active TB, a chest radiograph and medical evaluation should be obtained (Category II).

5 Follow-up TST for TB should be performed periodically or after discovery of a new case of TB in a resident or staff member (Category IB). No recommendation on frequency of routine follow-up TSTs for residents.

6 Each resident should receive current vaccinations for tetanus, diphtheria, influenza, pertussis, pneumococcal pneumonia, and any other vaccines recommended by the ACIP (Category IB/IC).

7 Each resident should receive the influenza vaccine annually in the fall, unless medically contraindicated (Category IC).

Comment: Facilities should obtain resident consent at admission for yearly influenza vaccination and use standing orders for yearly influenza vaccination.

8 Policies and procedures addressing visitors should be developed to limit introduction of community infections (such as influenza) into the LTCF (Category II).

\section{K. Employee health program}

1 All new employees should have a baseline health assessment, including immunization status and history of relevant past or present infectious diseases (Category 1B/IC)

Comment: The past history of infectious diseases should address contagious diseases such as chickenpox, measles, hepatitis, furunculosis, and bacterial diarrhea. Screening cultures of new employees are rarely indicated.

2 All new employees should receive TST unless there is written documentation that the employee had a positive reaction to a tuberculin test. When new or active TB is suggested by a positive TST result or by symptoms, a chest radiograph and medical evaluation should be obtained (Category $1 \mathrm{~A} / \mathrm{IC}$ ).

Comment: A 2-step booster TST technique is recommended when indicated. Only employees who have active pulmonary TB should be restricted from work.

3 Follow-up skin testing of staff who are TST negative should be performed periodically based on the facility's annual risk assessment or after discovery of a new case of TB in a resident or staff member (Category $1 \mathrm{~A} / \mathrm{IC}$ ).

Comment: The intradermal Mantoux method or licensed blood test should be used. The frequency of testing depends on the regional prevalence of TB; the facility's annual risk assessment; and federal, state, or local regulations.

4 All employees should have current immunizations as recommended for HCWs by the Advisory Committee 
on Immunization Practices (ACIP), with documentation in the employee record (Category $1 \mathrm{~A} / \mathrm{IC}$ ).

5 Employees with blood or body fluid contact should be offered HBV immunization within 10 working days of hire and after training has been completed (Category 1C).

Comment: Refusal of this vaccine should be documented, using the OSHA-required Declination Statement for Hepatitis B vaccine.

6 Employees should be offered the influenza vaccine annually (Category $1 \mathrm{~A} / 1 \mathrm{C}$ ).

Comment: Avaccine declination statement may be signed by each employee who declines influenza vaccination.

7 Each employee should be taught basic use of personal protective equipment and hand hygiene and to consider blood and all body fluids as potentially infectious (Category 1C).

8 Employees with signs or symptoms of communicable diseases (eg, cough, rash, diarrhea) should not have contact with the residents or their food (Category 1B).

9 All employees should be educated to report any significant infectious illnesses to their supervisor and the staff member responsible for employee health (Category 1B).

Comment: Each employee record should include factors affecting immune status (such as steroid therapy, diabetes, HIV infection), history of communicable diseases, illnesses, and incidents such as exposures to contagious diseases, needlesticks, injuries, and accidents.

10 The LTCF should develop protocols for managing employee illnesses and exposures (such as bloodborne pathogens like HIV and hepatitis B and C, as well as TB, scabies, or gastroenteritis) (Category $1 \mathrm{~B} / \mathrm{IC})$.

Comment: An employee absentee policy that discourages the employee from working while ill should be developed.

\section{Education}

1 Infection control education should be provided at the initiation of employment and regularly thereafter. Training should include all staff, especially those providing direct resident care (Category IC).

2 All programs should be documented with the date, topic, names of attendees, and evaluations (Category IC).

Comment: Program topics should be timely and relevant to infection prevention and control. Basic hygiene, hand hygiene, respiratory etiquette, transmission of infectious diseases, occupational health, prevention of TB and bloodborne pathogens, Standard and Transmission-based Precautions, infection control standards, and the susceptibility of residents to infectious diseases are topics that should be included. The ICP may recommend topics. Surveillance data are of interest to staff and may be included as appropriate. The educators should evaluate the educational program and outcomes and use that information to modify future programs.

\section{Policies and procedures}

1 Infection control policies and procedures dealing with relevant aspects of infection control such as hand hygiene, disinfection, and isolation precautions should be in place and compatible with current regulations and infection control knowledge (Category IC).

2 Infection control policies and procedures should be approved, reviewed, and revised on a regular basis (Category IC).

Comment: The ICP should assist in the development and updating of infection-related policies and procedures.

3 Employees should be made aware of infection control policies and procedures (Category IC).

Comment: The ICP should develop a system for monitoring staff compliance with infection control policies and procedures.

\section{N. Antibiotic stewardship}

1 Infection control programs in LTCFs should be encouraged to include a component of antimicrobial stewardship (Category IB).

Comment: The LTCF should encourage judicious use of antimicrobials with guidelines based in part on local susceptibility patterns. Antibiotic utilization and appropriateness may be monitored, and these data used for interventions (eg, education, antibiotic restrictions).

2 The ICP should monitor antibiotic susceptibility results from cultures to detect clinically significant antibiotic-resistant bacteria (such as MRSA or VRE) in the institution. Changes in antibiotic-susceptibility trends should be communicated to appropriate individuals and committees (Category IB).

\section{O. Miscellaneous aspects}

1 There should be a system for reporting notifiable diseases to proper public health officials (Category 1C). 
2 The infection control program should collaborate with the performance improvement (PI) program, if a formal program exists (Category II).

Comment: Infection control is an important component of PI, and the epidemiological techniques used in infection control will assist the PI program.

3 The ICP should be involved with the review and selection of new products that have infection control implications (Category II).

4 The ICP should be involved with LTCF influenza pandemic preparedness planning (Category II).

5 Infection control activities should address relevant resident safety issues (Category II).

\section{P. Regulations}

1 The infection control program must be in compliance with federal, state, and local regulations (Category IC).

2 The infection control program should reflect national, evidence-based standards of practice for infection prevention and control (Category IC).

The authors gratefully acknowledge the expert contribution of Chesley Richards, MD, of the CDC, and the editorial assistance of Elaine Litton of the University of Nebraska Medical Center.

\section{References}

I. American Health Care Association National Center forAssisted Living. Consumer information about long-term care-glossary of terms. Available at: http://longtermcareliving.com/glossary/. Accessed July 2008.

2. Haley RW, Culver DH, White JW, Morgan WM, Emori TG, Munn VP, et al. The efficacy of infection surveillance and control programs in preventing nosocomial infections in US hospitals. Am J Epidemiol 1985; I21:182-205.

3. Haley RW, Culver DH, White JW, Morgan WM, Emori TG. The nationwide nosocomial infection rate: a new need for vital statistics. Am J Epidemiol 1985;121:159-67.

4. Administration on Aging. Statistics on the aging population. Available at: http://www.aoa.gov/prof/Statistics/statistics.asp. Accessed July 2008.

5. AMA. American Medical Association white paper on elderly health: report of the Council on Scientific Affairs. Arch Intern Med 1990; 150:2459-72.

6. American Health Care Association. Oscar data reports: nursing facility total, average and median number of patients per facility and ADL dependence. Available at: http://ahca.org/research/oscar/rpt_average_ADL_2006/2.pdf. Accessed July 2008.

7. Smith PW, Rusnak PG. Infection prevention and control in the longterm-care facility. SHEA Long-Term Care Committee and APIC Guidelines Committee. Infect Control Hosp Epidemiol 1997; 18:83 I-9.

8. Strausbaugh LJ, Joseph CL. The burden of infection in long-term care. Infect Control Hosp Epidemiol 2000;21:674-9.

9. Strausbaugh LJ, Sukumar SR, Joseph CL. Infectious disease outbreaks in nursing homes: an unappreciated hazard for frail elderly persons. Clin Infect Dis 2003;36:870-6.

10. Castle SC. Clinical relevance of age-related immune dysfunction. Clin Infect Dis 2000;31:578-85.

II. Strausbaugh LJ. Emerging health care-associated infections in the geriatric population. Emerg Infect Dis 200I;7:268-7I.
12. Richards C. Infections in residents of long-term care facilities: an agenda for research. Report of an expert panel. J Am Geriatr Soc 2002;50:570-6.

13. Yoshikawa TT. Geriatric infectious diseases: an emerging problem. J Am Geriatr Soc 1983;31:34-9.

14. National Center for Health Statistics. 2004 Nursing HomeFacility Survey tables. Available at: http://www.cdc.gov/nchs/data/nnhsd/nur singhomefacilities2006.pdf\#0I. Accessed July 2008.

15. Richards CLJr, Darradji M, Weinberg A, Ouslander JG. Antimicrobial use in post-acute care: a retrospective descriptive analysis in seven longterm care facilities in Georgia. J Am Med Dir Assoc 2005;6: 109-12.

16. Zimmerman S, Gruber-Baldini AL, Hebel JR, Sloane PD, Magaziner J. Nursing home facility risk factors for infection and hospitalization: importance of registered nurse turnover, administration, and social factors. J Am Geriatr Soc 2002;50:1987-95.

17. Nicolle LE, Strausbaugh LJ, Garibaldi RA. Infections and antibiotic resistance in nursing homes. Clin Microbiol Rev 1996;9:1-17.

18. Stevenson KB, Moore J, Colwell H, Sleeper B. Standardized infection surveillance in long-term care: interfacility comparisons from a regional cohort of facilities. Infect Control Hosp Epidemiol 2005; 26:23I-8.

19. Smith PW. Infections in long-term care facilities. Infect Control 1985; 6:435-6.

20. Nicolle LE, Bradley S, Colgan R, Rice JC, Schaeffer A, Hooton TM, et al. Infectious Diseases Society of America Guidelines for the diagnosis and treatment of asymptomatic bacteriuria in adults. Clin Infect Dis 2005:40:643-54.

21. Ouslander JG, Schnelle JF. Incontinence in the nursing home. Ann Intern Med 1995; 122:438-49.

22. Nicolle LE, Henderson E, Bjornson J, Mclntyre M, Harding GK, MacDonell JA. The association of bacteriuria with resident characteristics and survival in elderly institutionalized men. Ann Intern Med 1987; 106:682-6.

23. McGeer A, Campbell B, Emori TG, Hierholzer WJ, Jackson MM, Nicolle LE, et al. Definitions of infection for surveillance in long-term care facilities. Am J Infect Control 1991;19:1-7.

24. Warren JW, Steinberg L, Hebel JR, Tenney JH. The prevalence of urethral catheterization in Maryland nursing homes. Arch Intern Med 1989;149:1535-7.

25. Kunin CM, Douthitt S, Dancing J, Anderson J, Moeschberger M. The association between the use of urinary catheters and morbidity and mortality among elderly patients in nursing homes. Am J Epidemiol 1992;135:29|-30|.

26. Ribeiro BJ, Smith SR. Evaluation of urinary catheterization and urinary incontinence in a general nursing home population. J Am Geriatr Soc 1985;33:479-82.

27. Warren JW, Tenney JH, Hoopes JM, Muncie HL, Anthony WC. A prospective microbiologic study of bacteriuria in patients with chronic indwelling urethral catheters. J Infect Dis 1982;146: 719-23.

28. Gambert SR, Duthie EH Jr, Priefer B, Rabinovitch RA. Bacterial infections in a hospital-based skilled nursing facility. J Chronic Dis 1982;35: $78 I-6$.

29. Daly PB, Smith PW, Rusnak PG, Woods GL. A microbiologic survey of long term care urinary catheters. Nebr Med J 1991;76:161-5.

30. Warren JW. Catheter-associated bacteriuria in long-term care facilities. Infect Control Hosp Epidemiol 1994;15:557-62.

31. Raz R, Schiller D, Nicolle LE. Chronic indwelling catheter replacement before antimicrobial therapy for symptomatic urinary tract infection. J Urol 2000;164:1254-8.

32. Wong ES, Hooten TM. Guideline for prevention of catheter-associated urinary tract infections. Infect Control 1981;2:125-30.

33. Duffy LM, Cleary J, Ahern S, Kuskowski MA, West M, Wheeler L, et al. Clean intermittent catheterization: safe, cost-effective bladder management for male residents of VA nursing homes. J Am Geriatr Soc 1995;43:865-70. 
34. Smith PW, Daly PB, Roccaforte JS. Current status of nosocomial infection control in extended care facilities. Am J Med 1991;91:S28I-5.

35. Saint S, Kaufman SR, Rogers MA, Baker PD, Ossenkop K, Lipsky BA. Condom versus indwelling urinary catheters: a randomized trial. J Am Geriatr Soc 2006;54:1055-6I.

36. Minister of National Health and Welfare Laboratory Centre for Disease Control. Infection control guidelines for long-term care facilities. Ottawa, Ontario, Canada: Canada Ministry of National Health and Welfare; 1994.

37. Garofalo K. Home health. In: Olmstead RN, editor. APIC infection control and applied epidemiology: principles and practice. St. Louis: Mosby; 1996.

38. Falsey AR. Noninfluenza respiratory virus infection in long-term care facilities. Infect Control Hosp Epidemiol 1991;12:602-8.

39. Drinka PJ, Gravenstein S, Langer E, Krause P, Shult P. Mortality following isolation of various respiratory viruses in nursing home residents. Infect Control Hosp Epidemiol 1999;20:8I2-5.

40. Boivin G, De Serres G, Hamelin ME, Côté S, Argouin M, Tremblay G, et al. An outbreak of severe respiratory tract infection due to human metapneumovirus in a long-term care facility. Clin Infect Dis 2007;44: II52-8.

4I. Loeb M, McGeer A, McArthur M, Walter S, Simor AE. Risk factors for pneumonia and other lower respiratory tract infections in elderly residents of long-term care facilities. Arch Intern Med 1999;159: 2058-64.

42. Mylotte JM. Nursing home-acquired pneumonia. Clin Infect Dis 2002; 35:I205-II.

43. Mylotte JM, Goodnough S, Naughton BJ. Pneumonia versus aspiration pneumonitis in nursing home residents: diagnosis and management. J Am Geriatr Soc 2003;51:17-23.

44. Marrie TJ. Pneumonia in the long-term-care facility. Infect Control Hosp Epidemiol 2002;23:159-64.

45. Naughton BJ, Mylotte JM, Tayara A. Outcome of nursing homeacquired pneumonia: derivation and application of a practical model to predict 30-day mortality. J Am Geriatr Soc 2000;48: 1292-9.

46. Bentley DW, Bradley S, High K, Schoenbaum S, Taler G, Yoshikawa TT, et al. Practice guideline for evaluation of fever and infection in long-term care facilities. Clin Infect Dis 2000;31:640-53.

47. Tan CG, Ostrawski S, Bresnitz EA. A preventable outbreak of pneumococcal pneumonia among unvaccinated nursing home residents in New Jersey during 200I. Infect Control Hosp Epidemiol 2003;24: 848-52.

48. Gleich S, Morad Y, Echague R, Miller JR, Kornblum J, Sampson JS, et al. Streptococcus pneumoniae serotype 4 outbreak in a home for the aged: report and review of recent outbreaks. Infect Control Hosp Epidemiol 2000;21:71I-7.

49. Kotilainen P, Routamaa M, Peltonen R, Evesti P, Eerola E, Salmenlinna $S$, et al. Eradication of methicillin-resistant Staphylococcus aureus from a health center ward and associated nursing home. Arch Intern Med 2001;161:859-63.

50. Mody L, Maheshwari S, Galecki A, Kauffman CA, Bradley SF. Indwelling device use and antibiotic resistance in nursing homes: identifying a high-risk group. J Am Geriatr Soc 2007;55:1921-6.

5I. Meehan TP, Chua-Reyes JM, Tate J, Prestwood KM, Scinto JD, Petrillo MK, et al. Process of care performance, patient characteristics, and outcomes in elderly patients hospitalized with community-acquired or nursing home-acquired pneumonia. Chest 2000; I 17:1378-85.

52. Fine MJ, Auble TE, Yealy DM, Hanusa BH, Weissfeld LA, Singer DE, et al. A prediction rule to identify low-risk patients with communityacquired pneumonia. N Engl J Med 1997;336:243-50.

53. Mylotte JM, Naughton B, Saludades C, Maszarovics Z. Validation and application of the pneumonia prognosis index to nursing home residents with pneumonia. J Am Geriatr Soc 1998;46:1538-44.

54. Tablan OC, Anderson LJ, Besser R, Bridges C, Hajjeh R, CDC, et al. Guidelines for preventing health-care-associated pneumonia,
2003: recommendations of CDC and the Healthcare Infection Control Practices Advisory Committee. MMWR Recomm Rep 2004;53:1-36.

55. CDC. Prevention of pneumococcal disease: recommendations of the Advisory Committee on Immunization Practices (ACIP). MMWR Recomm Rep 1997;46: I-24.

56. Watson L, Wilson BJ, Waugh N. Pneumococcal polysaccharide vaccine: a systematic review of clinical effectiveness in adults. Vaccine 2002;20:2166-73.

57. Loeb M, Stevenson KB. SHEA Long-Term-Care Committee. Pneumococcal immunization in older adults: implications for the longterm-care setting. Infect Control Hosp Epidemiol 2004;25:985-94.

58. Centers for Medicare and Medicaid Services (CMS)HHS. Medicare and Medicaid programs, condition of participation: immunization standard for long-term care facilities. Final rule. Fed Regist 2005; 70:58833-52.

59. Smith NM, Bresee JS, Shay DK, Uyeki TM, Cox NJ, et al, the Advisory Committee on Immunization Practices. Prevention and control of influenza: recommendations of the Advisory Committee on Immunization Practices (ACIP). MMWR Recomm Rep 2006; 55:I-42.

60. Bradley SF. Prevention of influenza in long-term-care facilities: LongTerm-Care Committee of the Society for Healthcare Epidemiology of America. Infect Control Hosp Epidemiol 1999;20:629-37.

61. Thompson WW, Shay DK, Weintraub E, Brammer L, Cox N, Anderson LJ, et al. Mortality associated with influenza and respiratory syncytial virus in the United States. JAMA 2003;289:179-86.

62. Zadeh MM, Buxton Bridges C, Thompson WW, Arden NH, Fukuda $\mathrm{K}$. Influenza outbreak detection and control measures in nursing homes in the united states. J Am Geriatr Soc 2000;48:1310-5.

63. Kohn MA, Farley TA, Sundin D, Tapia R, McFarland LM, Arden NH. Three summertime outbreaks of influenza type A. J Infect Dis 1995; 172:246-9.

64. Gravenstein S, Miller BA, Drinka P. Prevention and control of influenza A outbreaks in long-term care facilities. Infect Control Hosp Epidemiol 1992;13:49-54.

65. Patriarca PA, Weber JA, Parker RA, Hall WN, Kendal AP, Bregman $D J$, et al. Efficacy of influenza vaccine in nursing homes: reduction in illness and complications during an influenza $A(H 3 N 2)$ epidemic. JAMA 1985;253:1 136-9.

66. Gross PA, Hermogenes AW, Sacks HS, Lau J, Levandowski RA. The efficacy of influenza vaccine in elderly persons: a meta-analysis and review of the literature. Ann Intern Med 1995; 123:5 I8-27.

67. Gross PA, Quinnan GV, Rodstein M, LaMontagne JR, Kaslow RA, Saah AJ, et al. Association of influenza immunization with reduction in mortality in an elderly population: a prospective study. Arch Intern Med 1988; 148:562-5.

68. Monto AS, Rotthoff J, Teich E, Herlocher ML, Truscon R, Yen HL, et al. Detection and control of influenza outbreaks in well-vaccinated nursing home populations. Clin Infect Dis 2004;39:459-64.

69. Mody L, Langa KM, Saint S, Bradley SF. Preventing infections in nursing homes: a survey of infection control practices in southeast Michigan. Am J Infect Control 2005;33:489-92.

70. Mody L, Langa KM, Malani PN. Impact of the 2004-2005 influenza vaccine shortage on immunization practices in long-term care facilities. Infect Control Hosp Epidemiol 2006;27:383-7.

7I. Saah AJ, Neufeld R, Rodstein M, La Montagne JR, Blackwelder WC, Gross $\mathrm{P}$, et al. Influenza vaccine and pneumonia mortality in a nursing home population. Arch Intern Med 1986; 146:2353-7.

72. Arden $\mathrm{NH}$. Control of influenza in the long-term-care facility: a review of established approaches and newer options. Infect Control Hosp Epidemiol 2000;21:59-64.

73. Gravenstein S, Davidson HE. Current strategies for management of influenza in the elderly population. Clin Infect Dis 2002;35: 729-37. 
74. Stead WW, Lofgren JP, Warren E, Thomas C. Tuberculosis as an endemic and nosocomial infection among the elderly in nursing homes. N Engl J Med 1985;3 I2:1483-7.

75. Ijaz K, Dillaha JA, Yang Z, Cave MD, Bates JH. Unrecognized tuberculosis in a nursing home causing death with spread of tuberculosis to the community. J Am Geriatr Soc 2002;50:1213-8.

76. Narain JP, Lofgren JP, Warren E, Stead WW. Epidemic tuberculosis in a nursing home: a retrospective cohort study. J Am Geriatr Soc 1985; 33:258-63.

77. Price LE, Rutala WA. Tuberculosis screening in the long-term care setting. Infect Control 1987;8:353-6.

78. Thrupp L, Bradley S, Smith P, Simor A, Gantz N, Crossley K, et al. Tuberculosis prevention and control in long-term-care facilities for older adults. Infect Control Hosp Epidemiol 2004;25:1097-108.

79. CDC. Targeted tuberculin testing and treatment of latent tuberculosis infection. American Thoracic Society. MMWR Recomm Rep 2000; 49:1-5I.

80. American Thoracic Society, CDC, Infectious Diseases Society of America. Treatment of tuberculosis. MMWR Recomm Rep 2003; 52:1-77.

8I. Rajagopalan S. Tuberculosis and aging: a global health problem. Clin Infect Dis 2001;33:1034-9.

82. Naglie G, McArthur M, Simor A, Naus M, Cheung A, McGeer A. Tuberculosis surveillance practices in long-term care institutions. Infect Control Hosp Epidemiol 1995; I6:148-5I.

83. CDC and American Thoracic Society. Diagnostic standards and classification of tuberculosis in adults and children. This official statement of the American Thoracic Society and the Centers for Disease Control and Prevention was adopted by the ATS board of directors, July 1999. This statement was endorsed by the Council of the Infectious Disease Society of America, September 1999. Am J Respir Crit Care Med 2000; 161:1376-95.

84. Institute of Medicine (US). Committee on the Elimination of Tuberculosis in the United States. In: Geiter L, editor. Ending neglect: the elimination of tuberculosis in the United States. Washington, DC: National Academy Press; 2000.

85. Jensen PA, Lambert LA, lademarco MF, Ridzon R, CDC. Guidelines for preventing the transmission of Mycobacterium tuberculosis in health-care settings, 2005. MMWR Recomm Rep 2005;54:I-I4I.

86. Garcia AD, Thomas DR. Assessment and management of chronic pressure ulcers in the elderly. Med Clin North Am 2006;90: 925-44.

87. Brandeis GH, Morris JN, Nash DJ, Lipsitz LA. The epidemiology and natural history of pressure ulcers in elderly nursing home residents. JAMA 1990;264:2905-9.

88. Livesley NJ, Chow AW. Infected pressure ulcers in elderly individuals. Clin Infect Dis 2002;35:1390-6.

89. Lyder $\mathrm{CH}$. Pressure ulcer prevention and management. JAMA 2003; 289:223-6.

90. Gupta S, Baharestani M, Baranoski S, de Leon J, Engel SJ, MendezEastman S, et al. Guidelines for managing pressure ulcers with negative pressure wound therapy. Adv Skin Wound Care 2004; I7(Suppl 2): I-16.

91. Auerbach SB, Schwartz B, Williams D, Fiorilli MG, Adimora AA, Breiman RF, et al. Outbreak of invasive group $A$ streptococcal infections in a nursing home: lessons on prevention and control. Arch Intern Med 1992;152:1017-22.

92. Schwartz B, Ussery XT. Group A streptococcal outbreaks in nursing homes. Infect Control Hosp Epidemiol 1992;13:742-7.

93. Greene CM, Van Beneden CA, Javadi M, Skoff TH, Beall B, Facklam R, et al. Cluster of deaths from group $A$ streptococcus in a long-term care facility-Georgia, 200 I. Am J Infect Control 2005;33:108-I3.

94. Andersen BM, Haugen $H$, Rasch M, Heldal Haugen A, Tageson A. Outbreak of scabies in Norwegian nursing homes and home care patients: control and prevention. J Hosp Infect 2000;45:160-4.
95. Wilson MM, Philpott CD, Breer WA. Atypical presentation of scabies among nursing home residents. J Gerontol A Biol Sci Med Sci 200I; 56:M424-7.

96. de Beer G, Miller MA, Tremblay L, Monette J. An outbreak of scabies in a long-term care facility: the role of misdiagnosis and the costs associated with control. Infect Control Hosp Epidemiol 2006;27: 517-8.

97. Chosidow O. Scabies and pediculosis. Lancet 2000;355:8/9-26.

98. Scheinfeld N. Controlling scabies in institutional settings: a review of medications, treatment models, and implementation. Am J Clin Dermatol 2004;5:3I-7.

99. Augustin AK, Simor AE, Shorrock C, McCausland J. Outbreaks of gastroenteritis due to Norwalk-like virus in two long-term care facilities for the elderly. Can J Infect Control 1995; 10: I I I-3.

100. Green KY, Belliot G, Taylor JL, Valdesuso J, Lew JF, Kapikian AZ, et al. A predominant role for Norwalk-like viruses as agents of epidemic gastroenteritis in Maryland nursing homes for the elderly. J Infect Dis 2002; 185:133-46.

101. Slotwiner-Nie PK, Brandt LJ. Infectious diarrhea in the elderly. Gastroenterol Clin North Am 200 I;30:625-35.

102. Olsen SJ, DeBess EE, McGivern TE, Marano N, Eby T, Mauvais S, et al. A nosocomial outbreak of fluoroquinolone-resistant salmonella infection. N Engl J Med 200I;344:1572-9.

103. Carter AO, Borczyk AA, Carlson JA, Harvey B, Hockin JC, Karmali MA, et al. A severe outbreak of Escherichia coli OI57:H7-associated hemorrhagic colitis in a nursing home. N Engl J Med 1987;317: 1496-500.

104. Simor AE, Bradley SF, Strausbaugh LJ, Crossley K, Nicolle LE. SHEA Long-Term-Care Committee. Clostridium difficile in long-term-care facilities for the elderly. Infect Control Hosp Epidemiol 2002;23: 696-703.

105. Winquist AG, Roome A, Mshar R, Fiorentino T, Mshar P, Hadler J. Outbreak of campylobacteriosis at a senior center. J Am Geriatr Soc 200I;49:304-7.

106. White KE, Hedberg CW, Edmonson LM, Jones DB, Osterholm MT, MacDonald KL. An outbreak of giardiasis in a nursing home with evidence for multiple modes of transmission. J Infect Dis 1989;160:298-304.

107. Bennett RG. Diarrhea among residents of long-term care facilities. Infect Control Hosp Epidemiol 1993;14:397-404.

108. CDC. Diagnosis and management of foodborne illnesses. A primer for physicians and other health care professionals. MMWR Recomm Rep 2004;53:I-33.

109. Setia U, Serventi I, Lorenz P. Bacteremia in a long-term care facility: spectrum and mortality. Arch Intern Med 1984; 144:1633-5.

110. Mylotte JM, Tayara A, Goodnough S. Epidemiology of bloodstream infection in nursing home residents: evaluation in a large cohort from multiple homes. Clin Infect Dis 2002;35: 1484-90.

III. Muder RR, Brennen C, Wagener MM, Goetz AM. Bacteremia in a long-term-care facility: a five-year prospective study of 163 consecutive episodes. Clin Infect Dis 1992; 14:647-54.

I 12. O'Grady NP, Alexander M, Dellinger EP, Gerberding JL, Heard SO, Maki DG, et al. Guidelines for the prevention of intravascular catheter-related infections. Centers for Disease Control and Prevention. MMWR Recomm Rep 2002;5 I: I-29.

113. Garibaldi RA, Brodine S, Matsumiya S. Infections among patients in nursing homes: policies, prevalence, problems. N Engl J Med 198I; 305:73I-5.

114. Boustcha E, Nicolle LE. Conjunctivitis in a long-term care facility. Infect Control Hosp Epidemiol 1995; 16:210-6.

II5. Drinka PJ, Stemper ME, Gauerke CD, Miller JE, Goodman BM, Reed KD. Clustering of multiple endemic strains of methicillin-resistant Staphylococcus aureus in a nursing home: an 8-year study. Infect Control Hosp Epidemiol 2005;26:2/5-8.

116. Centers for Disease Control and Prevention. Surveillance for epidemics. MMWR Recomm Rep 1989;38:694-6. 
1 17. Ryan CA, Tauxe RV, Hosek GW, Wells JG, Stoesz PA, McFadden HW Jr, et al. Escherichia coli O 157:H7 diarrhea in a nursing home: Clinical, epidemiological, and pathological findings. J Infect Dis 1986;154: $631-8$.

1 18. Arnold KE, Schweitzer JL, Wallace B, Salter M, Neeman R, Hlady WG, et al. Tightly clustered outbreak of group a streptococcal disease at a long-term care facility. Infect Control Hosp Epidemiol 2006;27:1377-84.

119. Bentley DW. Clostridium difficile-associated disease in long-term care facilities. Infect Control Hosp Epidemiol 1990; I I:434-8.

120. Standaert SM, Hutcheson RH, Schaffner W. Nosocomial transmission of salmonella gastroenteritis to laundry workers in a nursing home. Infect Control Hosp Epidemiol 1994;15:22-6.

121. Troy CJ, Peeling RW, Ellis AG, Hockin JC, Bennett DA, Murphy MR, et al. Chlamydia pneumoniae as a new source of infectious outbreaks in nursing homes. JAMA 1997;277:1214-8.

122. Nakashima K, Tanaka T, Kramer MH, Takahashi H, Ohyama T, Kishimoto $\mathrm{T}$, et al. Outbreak of Chlamydia pneumoniae infection in a Japanese nursing home, 1999-2000. Infect Control Hosp Epidemiol 2006; 27:1171-7.

123. Seenivasan MH, Yu VL, Muder RR. Legionnaires' disease in long-term care facilities: overview and proposed solutions. J Am Geriatr Soc 2005;53:875-80.

124. Rodriguez EM, Parrott C, Rolka H, Monroe SS, Dwyer DM. An outbreak of viral gastroenteritis in a nursing home: importance of excluding ill employees. Infect Control Hosp Epidemiol 1996;17: 587-92.

125. Levine WC, Smart JF, Archer DL, Bean NH, Tauxe RV. Foodborne disease outbreaks in nursing homes, 1975 through 1987. JAMA 1991;266:2105-9.

126. Musher DM, Musher BL. Contagious acute gastrointestinal infections. N Engl J Med 2004;35I:2417-27.

127. Khan AJ, Cotter SM, Schulz B, Hu X, Rosenberg J, Robertson BH, et al. Nosocomial transmission of hepatitis $B$ virus infection among residents with diabetes in a skilled nursing facility. Infect Control Hosp Epidemiol 2002;23:313-8.

128. Shlaes DM, Lehman MH, Currie-McCumber CA, Kim CH, Floyd R. Prevalence of colonization with antibiotic resistant gram-negative bacilli in a nursing home care unit: the importance of cross-colonization as documented by plasmid analysis. Infect Control 1986;7: $538-45$.

129. John JF Jr, Ribner BS. Antibiotic resistance in long-term care facilities. Infect Control Hosp Epidemiol 1991;12:245-50.

130. Muder RR, Brennen C, Wagener MM, Vickers RM, Rihs JD, Hancock $\mathrm{GA}$, et al. Methicillin-resistant staphylococcal colonization and infection in a long-term care facility. Ann Intern Med 1991;1 14:107-12.

131. Bradley SF, Terpenning MS, Ramsey MA, Zarins LT, Jorgensen KA, Sottile WS, et al. Methicillin-resistant Staphylococcus aureus: colonization and infection in a long-term care facility. Ann Intern Med 1991; II 5:417-22.

132. Strausbaugh LJ, Jacobson C, Sewell DL, Potter S, Ward TT. Methicillin-resistant Staphylococcus aureus in extended-care facilities: experiences in a Veterans' Affairs nursing home and a review of the literature. Infect Control Hosp Epidemiol 1991;12:36-45.

133. Boyce JM. Methicillin-resistant Staphylococcus aureus in hospitals and long-term care facilities: microbiology, epidemiology, and preventive measures. Infect Control Hosp Epidemiol 1992;13:725-37.

134. Viray M, Linkin D, Maslow JN, Stieritz DD, Carson LS, Bilker WB, et al. Longitudinal trends in antimicrobial susceptibilities across long-termcare facilities: emergence of fluoroquinolone resistance. Infect Control Hosp Epidemiol 2005;26:56-62.

135. Flournoy $D J$. Antimicrobial susceptibilities of bacteria from nursing home residents in Oklahoma. Gerontology 1994;40:53-6.

136. Trick WE, Weinstein RA, DeMarais PL, Kuehnert MJ, Tomaska W, Nathan $C$, et al. Colonization of skilled-care facility residents with 3antimicrobial-resistant pathogens. J Am Geriatr Soc 200I;49: 270-6.

137. Fry AM, Udeagu CC, Soriano-Gabarro M, Fridkin S, Musinski D, LaClaire $\mathrm{L}$, et al. Persistence of fluoroquinolone-resistant, multidrugresistant Streptococcus pneumoniae in a long-term-care facility: efforts to reduce intrafacility transmission. Infect Control Hosp Epidemiol 2005;26:239-47.

138. Suetens C, Niclaes L, Jans B, Verhaegen J, Schuermans A, Van Eldere J, et al. Methicillin-resistant Staphylococcus aureus colonization is associated with higher mortality in nursing home residents with impaired cognitive status. J Am Geriatr Soc 2006;54:1854-60.

139. Capitano B, Nicolau DP. Evolving epidemiology and cost of resistance to antimicrobial agents in long-term care facilities. J Am Med Dir Assoc 2003;4:590-9.

140. Lautenbach E, Fishman NO, Bilker WB, Castiglioni A, Metlay JP, Edelstein $\mathrm{PH}$, et al. Risk factors for fluoroquinolone resistance in nosocomial Escherichia coli and Klebsiella pneumoniae infections. Arch Intern Med 2002; 162:2469-77.

14I. Lautenbach E, Strom BL, Bilker WB, Patel JB, Edelstein PH, Fishman NO. Epidemiological investigation of fluoroquinolone resistance in infections due to extended-spectrum $\beta$-lactamase-producing Escherichia coli and Klebsiella pneumoniae. Clin Infect Dis 2001;33:1288-94.

142. Byers KE, Anglim AM, Anneski CJ, Farr BM. Duration of colonization with vancomycin-resistant enterococcus. Infect Control Hosp Epidemiol 2002;23:207-II.

143. Montecalvo MA, de Lencastre H, Carraher M, Gedris C, Chung M, VanHorn K, et al. Natural history of colonization with vancomycinresistant Enterococcus faecium. Infect Control Hosp Epidemiol 1995; 16:680-5.

144. Lautenbach E, Tolomeo P, Mao X, Fishman NO, Metlay JP, Bilker WB, et al. Duration of outpatient fecal colonization due to Escherichia coli isolates with decreased susceptibility to fluoroquinolones: longitudinal study of patients recently discharged from the hospital. Antimicrob Agents Chemother 2006;50:3939-43.

145. Graham PL Lin SX III, Larson EL. A US population-based survey of Staphylococcus aureus colonization. Ann Intern Med 2006;144: 318-25.

146. Faulkner CM, Cox HL, Williamson JC. Unique aspects of antimicrobial use in older adults. Clin Infect Dis 2005;40:997-1004.

147. Wendt C, Svoboda D, Schmidt C, Bock-Hensley O, von Baum H. Characteristics that promote transmission of Staphylococcus aureus nursing homes in German nursing homes. Infect Control Hosp Epidemiol 2005;26:8I6-2I.

148. Boyce JM, Jackson MM, Pugliese G, Batt MD, Fleming D, Garner JS, et al. Methicillin-resistant Staphylococcus aureus (MRSA): A briefing for acute care hospitals and nursing facilities. The AHA Technical Panel on infections within hospitals. Infect Control Hosp Epidemiol 1994;15:105-15.

149. Price LE, Sarubbi FA Jr, Rutala WA. Infection control programs in twelve North Carolina extended care facilities. Infect Control 1985;6:437-4I.

150. Crossley KB, Irvine P, Kaszar DJ, Loewenson RB. Infection control practices in Minnesota nursing homes. JAMA 1985;254: 2918-2I.

15I. Khabbaz RF, Tenney JH. Infection control in Maryland nursing homes. Infect Control Hosp Epidemiol 1988;9:159-62.

152. Pearson DA, Checko PJ, Hierholzer WJ Jr, Jekel JF. Infection control practices in Connecticut's skilled nursing facilities. Am J Infect Control 1990;18:269-76.

153. Pearson DA, Checko PJ, Hierholzer WJ Jr, Jekel JF. Infection control practitioners and committees in skilled nursing facilities in Connecticut. Am J Infect Control 1990; 18:167-75.

154. Goldrick B, Larson E. Assessment of infection control programs in Maryland skilled-nursing long-term care facilities. Am J Infect Control 1994;22:83-9. 
155. Roup BJ, Roche JC, Pass M. Infection control program disparities between acute and long-term care facilities in Maryland. Am J Infect Control 2006;34:122-7.

156. Smith PW, Helget V, Sonksen D. Survey of infection control training program graduates: long-term care facility and small hospital practitioners. Am J Infect Control 2002;30:3 I I-3.

157. Yoshikawa TT, Ouslander JG. Infection management for geriatrics in long-term care facilities. New York: Marcel Dekker; 2002.

158. Collier WM, Collier WM. Matthew Bender. The Omnibus Budget Reconciliation Act of 1987, Public Law No. 100-203: As Amending ERISA with Respect to Pension Plans in Cases Under the Bankruptcy Code. New York, NY: M. Bender; 1988.

159. Medicare and Medicaid. Requirements for long-term care facilities-HCFA. Final rule. Fed Regist 1991;56:48826-80.

160. US Department of Health and Human Services, Centers for Medicare and Medicaid Services. Part 483-requirements for states and longterm care facilities. Section 483.65. Available at : http://www.globalaging. org/health/us/2005/unnecessary\%20drug.pdf. Accessed July 2008.

16I. American Health Care Association. The Long-Term Care SurveyWashington, DC: American Health Care Association; 2005.

162. Occupational exposure to bloodborne pathogens-OSHA. Final rule. Fed Regist 1991;56:64004-182.

163. Occupational exposure to bloodborne pathogens; needlestick and other sharps injuries. Final rule. Occupational Safety and Health Administration (OSHA), Department of Labor. Final rule: request for comment on the information collection (paperwork) requirements. Fed Regist 2001;66:5318-25.

164. Facilities Guidelines Institute. AIA Academy of Architecture for Health. 2006 Guidelines for Design and Construction of Health Care Facilities. Washington, DC: AIA 2006.

165. Joint Commission Resources on Accreditation of Healthcare Organizations. Comprehensive Accreditation Manuals for Long Term Care. Chicago, IL: Joint Commission on Accreditation of Healthcare Organizations; 2006.

166. Health Canada. Development of a resource model for infection prevention and control programs in acute, long term, and home care settings: Conference Proceedings of the Infection Prevention and Control Alliance. Am J Infect Control 2004;32:2-6.

167. Friedman C, Barnette M, Buck AS, Ham R, Harris JA, Hoffman $P$, et al. Requirements for infrastructure and essential activities of infection control and epidemiology in out-of-hospital settings: a consensus panel report. Association for Professionals in Infection Control and Epidemiology and Society for Healthcare Epidemiology of America. Infect Control Hosp Epidemiol 1999;20: 695-705.

168. Wendt $\mathrm{C}$, Bock-Hensley $\mathrm{O}$, von Baum $\mathrm{H}$. Infection control in German nursing homes. Am J Infect Control 2006;34:426-9.

169. Mayon-White R, Grant-Casey J. Infection control in British nursing homes. Infect Control Hosp Epidemiol 2003;24:296-8.

170. Murphy CL, McLaws ML. Who coordinates infection control programs in Australia? Am J Infect Control 1999;27:291-5.

171. Harris JA. Infection control in pediatric extended care facilities. Infect Control Hosp Epidemiol 2006;27:598-603.

172. Smith PW, Rusnak PG. APIC guideline for infection prevention and control in the long-term care facility. Am J Infect Control 1991;19: 198-2I5.

173. Nicolle LE. Infection control in long-term care facilities. Clin Infect Dis 2000;31:752-6.

174. Goldrick BA. Infection control programs in long-term-care facilities: structure and process. Infect Control Hosp Epidemiol 1999;20: 764-9.

175. Nicolle LE, Garibaldi RA. Infection control in long-term care facilities. In: Lautenbach E, Woeltje KF, Thorofare NJ, editors. Practical handbook for healthcare epidemiology. 2nd ed. Slack, Inc.; 2004. p. $275-80$.
176. Bradley SF. Infections and infection control in the long-term care setting. In: Yoshikawa TT, Norman DC, editors. Infectious disease in the aging, a clinical handbook. Totowa, NJ: Humana Press; 2000. p. 245-56.

177. Mody L. Establishing an infection control program. In: Yoshikawa TT, Ouslander JG, editors. Infection management for geriatrics in longterm care facilities. 2nd ed. New York, NY: Marcel Dekker, Inc; 2006. p. II5-30.

178. Horan-Murphy E, Barnard B, Chenoweth C, Friedman C, Hazuka B, Russell B, et al. APIC/CHICA-Canada infection control and epidemiology: professional and practice standards. Association for Professionals in Infection Control and Epidemiology, Inc, and the Community and Hospital Infection Control Association-Canada. Am J Infect Control 1999;27:47-5I.

179. Lee TB, Baker OG, Lee JT, Scheckler WE, Steele L, Laxton CE. Recommended practices for surveillance. Association for Professionals in Infection Control and Epidemiology, Inc., Surveillance Initiative Working Group. Am J Infect Control 1998;26:277-88.

180. Garner JS, Jarvis WR, Emori TG, Horan TC, Hughes JM. CDC definitions for nosocomial infections, 1988. Am J Infect Control 1988; 16:128-40.

18I. Smith PW. Infection surveillance in long-term care facilities. Infect Control Hosp Epidemiol 1991;12:55-8.

182. Satterfield N. Infection control in long-term care facilities: the hospitalbased practitioner's role. Infect Control Hosp Epidemiol I 993; 1 4:40-7.

183. Smith PW. Consensus conference on nosocomial infections in longterm care facilities. Am J Infect Control 1987;15:97-100.

184. McKibben L, Horan TC, Tokars JI, Fowler G, Cardo DM, Pearson ML, et al. Guidance on public reporting of health care-associated infections: recommendations of the Healthcare Infection Control Practices Advisory Committee. Infect Control Hosp Epidemiol 2005;26:580-7.

185. Stevenson KB. Regional data set of infection rates for long-term care facilities: description of a valuable benchmarking tool. Am J Infect Control 1999;27:20-6.

186. Rusnak PG. Long-term care. In: Olmstead R, editor. APIC infection control and applied epidemiology: principles and practice. St. Louis, MO: Mosby Year Book, Inc.; 1996.

187. Smith PW. Infection control in long-term care facilities. 2nd ed. Albany, NY: Delmar Publishers; 1994.

188. Vlahov D, Tenney JH, Cervino KW, Shamer DK. Routine surveillance for infections in nursing homes: experience at two facilities. Am J Infect Control 1987;15:47-53.

189. Centers for Disease Control andPrevention. Infection control measures for preventing and controlling influenza transmission in longterm care facilities. Available at: http://www.cdc.gov/flu/professionals/ infectioncontrol/longtermcare.htm.

190. Stern JK, Smith PW. Tuberculosis in the long-term care facility. Geriatr Focus Infect Dis 1991;1:6-10.

191. Beck-Sague C, Soto-Caceres V, Jarvis WR. Outbreak investigations (chapter 10). In: Lautenbach E, Woeltje KF, editors. Practical handbook for healthcare epidemiologists. 2nd ed. Thorofare, NJ: Slack; 2004. p. 373.

192. Oteo J, Navarro C, Cercenado E, Delgado-Iribarren A, Wilhelmi I, Orden B, et al. Spread of Escherichia coli strains with high-level cefotaxime and ceftazidime resistance between the community, longterm care facilities, and hospital institutions. J Clin Microbiol 2006; 44:2359-66.

193. Wiener J, Quinn JP, Bradford PA, Goering RV, Nathan C, Bush K, et al. Multiple antibiotic-resistant Klebsiella and Escherichia coli in nursing homes. JAMA 1999;281:517-23.

194. National Communicable Disease Center. Isolation techniques for use in hospitals. PHS publication No. 2054. Ist ed. Washington, DC: US Government Printing Office; 1970.

195. Garner JS, Simmons BP. Guideline for isolation precautions in hospitals. Infect Control 1983;4:245-325. 
196. Centers for Disease Control (CDC). Update: universal precautions for prevention of transmission of human immunodeficiency virus, hepatitis B virus, and other bloodborne pathogens in health-care settings. MMWR Morb Mortal Wkly Rep 1988;37: 377-82 387-8.

197. Centers for Disease Control. Recommendations for prevention of HIV transmission in health-care settings. MMWR Morb Mortal Wkly Rep 1987;36: I8-188.

198. Decker MD. The OSHA bloodborne hazard standard. Infect Control Hosp Epidemiol 1992;13:407-17.

199. Garner JS. Guideline for isolation precautions in hospitals. The Hospital Infection Control Practices Advisory Committee. Infect Control Hosp Epidemiol 1996; 17:53-80.

200. Siegel JD, Rhinehart E, Jackson M, Chiarello L, Hicpac. Management of multidrug-resistant organisms in healthcare settings, 2006. Available at: http://www.cdc.gov/ncidod/dhqp/pdf/ar/mdroGuideline2006.pdf. Accessed July 2008.

20I. Siegel JD, Rhinehart E, Jackson M, Chiarello L, the Healthcare Infection Control Practices Advisory Committee. 2007 Guideline for isolation precautions: preventing transmission of infectious agents in healthcare settings. Available at: http://www.cdc.gov/ncidod/dhqp/ pdf/guidelines/Isolation2007.pdf. Accessed July 2008.

202. Kreman T, Hu J, Pottinger J, Herwaldt LA. Survey of long-term-care facilities in lowa for policies and practices regarding residents with methicillin-resistant Staphylococcus aureus or vancomycin-resistant Enterococci. Infect Control Hosp Epidemiol 2005;26:8I I-5.

203. Geditz AF, Potter JF, Vandenberg EV, Smith LM, Smith PW. Isolation practices in Nebraska long-term-care facilities: a survey. Infect Dis Clin Pract 2005; 13:236-40.

204. Trick WE, Weinstein RA, DeMarais PL, Tomaska W, Nathan C, McAllister SK, et al. Comparison of routine glove use and contact-isolation precautions to prevent transmission of multidrug-resistant bacteria in a long-term care facility. J Am Geriatr Soc 2004; 52:2003-9.

205. Bradley SF. Issues in the management of resistant bacteria in longterm-care facilities. Infect Control Hosp Epidemiol 1999;20:362-6.

206. Recommendations for preventing the spread of vancomycin resistance. Recommendations of the Hospital Infection Control Practices Advisory Committee (HICPAC). MMWR Recomm Rep 1995;44: I-I3.

207. Bula CJ, Ghilardi G, Wietlisbach V, Petignat C, Francioli P. Infections and functional impairment in nursing home residents: a reciprocal relationship. J Am Geriatr Soc 2004;52:700-6.

208. Strausbaugh LJ, Crossley KB, Nurse BA, Thrupp LD. Antimicrobial resistance in long-term-care facilities. Infect Control Hosp Epidemiol 1996; 17:129-40.

209. Crossley K. Vancomycin-resistant enterococci in long-term-care facilities. Infect Control Hosp Epidemiol 1998;19:521-5.

210. Silverblatt FJ, Tibert C, Mikolich D, Blazek-D'Arezzo J, Alves J, Tack $M$, et al. Preventing the spread of vancomycin-resistant enterococci in a long-term care facility. J Am Geriatr Soc 2000;48: I I I -5.

211. Beltrami EM, Kozak A, Williams IT, Saekhou AM, Kalish ML, Nainan $\mathrm{OV}$, et al. Transmission of HIV and hepatitis $C$ virus from a nursing home patient to a health care worker. Am J Infect Control 2003; $31: 168-75$.

212. Centers for Disease Control and Prevention (CDC). Updated US public health service guidelines for the management of occupational exposures to HIV and recommendations for postexposure prophylaxis. MMWR Morb Mortal Wkly Rep 2005;54:I- 17.

213. Thompson BL, Dwyer DM, Ussery XT, Denman S, Vacek P, Schwartz B. Handwashing and glove use in a long-term-care facility. Infect Control Hosp Epidemiol 1997; 18:97-103.

214. Centers for Disease Control and Prevention (CDC). Handwashing and glove use in a long-term-care facility-Maryland, 1992. MMWR Morb Mortal Wkly Rep 1993;42:672-5.
215. Larson E, Bobo L, Bennett R, Murphy S, Seng ST, Choo JT, et al. Lack of caregiver hand contamination with endemic bacterial pathogens in a nursing home. Am J Infect Control 1992;20: I I-5.

216. Fendler EJ, Ali Y, Hammond BS, Lyons MK, Kelley MB, Vowell NA. The impact of alcohol hand sanitizer use on infection rates in an extended care facility. Am J Infect Control 2002;30:226-33.

217. Boyce JM, Pittet D. Healthcare Infection Control Practices Advisory Committee. Society for Healthcare Epidemiology of America. Association for Professionals in Infection Control. Infectious Diseases Society of America. Hand Hygiene Task Force. Guideline for hand hygiene in health-care settings: recommendations of the Healthcare Infection Control Practices Advisory Committee and the HICPAC/SHEA/APIC/IDSA Hand Hygiene Task Force. Infect Control Hosp Epidemiol 2002;23:S3-40.

218. Larson E. Guideline for use of topical antimicrobial agents. Am J Infect Control 1988;16:253-66.

219. Larson EL. APIC guideline for handwashing and hand antisepsis in health care settings. Am J Infect Control 1995;23:25I-69.

220. Centers for Disease Control and Prevention (CDC). Pneumococcal polysaccharide vaccine. MMWR Morb Mortal Wkly Rep 1989;38: 64-8 73-6.

221. Richardson JP. Tetanus and tetanus immunization in long-term care facilities. Infect Control Hosp Epidemiol 1993; 14:591-4.

222. Richardson JP, Knight AL. The prevention of tetanus in the elderly. Arch Intern Med 1991;151:1712-7.

223. Gardner P, Eickhoff T, Poland GA, Gross P, Griffin M, LaForce FM, et al. Adult immunizations. Ann Intern Med 1996;124:35-40.

224. Centers for Disease Control and Prevention (CDC). Facilitating influenza and pneumococcal vaccination through standing orders programs. MMWR Morb Mortal Wkly Rep 2003;52:68-9.

225. Murphy S, West KP Jr, Greenough WB III, Cherot E, Katz J, Clement L. Impact of vitamin A supplementation on the incidence of infection in elderly nursing-home residents: a randomized controlled trial. Age Ageing 1992;21:435-9.

226. Liu BA, McGeer A, McArthur MA, Simor AE, Aghdassi E, Davis L, et al. Effect of multivitamin and mineral supplementation on episodes of infection in nursing home residents: a randomized, placebo-controlled study. J Am Geriatr Soc 2007;55:35-42.

227. Sepkowitz KA. Occupationally acquired infections in health care workers. Part I. Ann Intern Med 1996;125:826-34.

228. Sepkowitz KA. Occupationally acquired infections in health care workers. Part II. Ann Intern Med 1996;125:917-28.

229. Diekema DJ, Doebbeling BN. Employee health and infection control. Infect Control Hosp Epidemiol 1995;16:292-301.

230. CDC. Immunization of health-care workers: recommendations of the Advisory Committee on Immunization Practices (ACIP) and the Hospital Infection Control Practices Advisory Committee (HICPAC). MMWR Recomm Rep 1997;46: I-42.

23I. Prevention and control of tuberculosis in facilities providing longterm care to the elderly: recommendations of the Advisory Committee for Elimination of Tuberculosis. MMWR Recomm Rep 1990;39: 7-13.

232. Centers for Disease Control and Prevention. Guidelines for preventing transmission of Mycobacterium tuberculosis in health-care settings, 2005. MMWR Morb Mortal Wkly Rep 2005;54:I-I4I.

233. Leinbach RM, English AJ. Training needs of infection control professionals in long-term care facilities in Virginia. Am J Infect Control 1995;23:73-7.

234. Smith PW, Daly PB, Rusnak PG, Roccaforte JS. Design and dissemination of a multiregional long-term care infection control training program. Am J Infect Control 1992;20:275-7.

235. Daly PB, Smith PW, Rusnak PG, Jones MB, Giuliano D. Impact on knowledge and practice of a multiregional long-term care facility infection control training program. Am J Infect Control 1992;20: 225-33. 
236. Maslow JN, Lee B, Lautenbach E. Fluoroquinolone-resistant Escherichia coli carriage in long-term care facility. Emerg Infect Dis 2005; I I:889-94.

237. Richards CL Jr, Steele L. Antimicrobial-resistant bacteria in long-term care facilities: infection control considerations. J Am Med Dir Assoc 2003;4:SI 10-4.

238. Loeb MB, Craven S, McGeer AJ, Simor AE, Bradley SF, Low DE, et al. Risk factors for resistance to antimicrobial agents among nursing home residents. Am J Epidemiol 2003; 157:40-7.

239. Cohen AE, Lautenbach E, Morales KH, Linkin DR. Fluoroquinoloneresistant Escherichia coli in the long-term care setting. Am J Med 2006; I 19:958-63.

240. Sandoval C, Walter SD, McGeer A, Simor AE, Bradley SF, Moss LM, et al. Nursing home residents and enterobacteriaceae resistant to third-generation cephalosporins. Emerg Infect Dis 2004; 10:1050-5.

24I. Nicolle LE, Bentley DW, Garibaldi R, Neuhaus EG, Smith PW. Antimicrobial use in long-term-care facilities. SHEA Long-term Care Committee. Infect Control Hosp Epidemiol 2000;21:537-45.

242. Zimmer JG, Bentley DW, Valenti WM, Watson NM. Systemic antibiotic use in nursing homes: a quality assessment. J Am Geriatr Soc 1986;34:703-10.

243. Jones SR, Parker DF, Liebow ES, Kimbrough RC III, Frear RS. Appropriateness of antibiotic therapy in long-term care facilities. Am J Med 1987;83:499-502

244. Warren JW, Palumbo FB, Fitterman L, Speedie SM. Incidence and characteristics of antibiotic use in aged nursing home patients. J Am Geriatr Soc 1991;39:963-72.

245. Loeb M, Simor AE, Landry L, Walter S, McArthur M, Duffy J, et al. Antibiotic use in Ontario facilities that provide chronic care. J Gen Intern Med 200I;I6:376-83.

246. Katz PR, Beam TR Jr, Brand F, Boyce K. Antibiotic use in the nursing home: Physician practice patterns. Arch Intern Med 1990; I50: I465-8.

247. Mylotte JM, Keagle J. Benchmarks for antibiotic use and cost in longterm care. J Am Geriatr Soc 2005;53: I I 17-22.

248. Smith PW, Seip CW, Schaefer SC, Bell-Dixon C. Microbiologic survey of long-term care facilities. Am J Infect Control 2000;28:8-I3.

249. O'Fallon E, Harper J, Shaw S, Lynfield R. Antibiotic and infection tracking in Minnesota long-term care facilities. J Am Geriatr Soc 2007;55:1243-7.

250. Dellit TH, Owens RC, McGowan JE Jr, Gerding DN, Weinstein RA, Burke JP, et al. Infectious Diseases Society of America and the Society for Healthcare Epidemiology of America guidelines for developing an institutional program to enhance antimicrobial stewardship. Clin Infect Dis 2007;44:159-77.

25I. Gahr P, Harper J, Kieke B Jr, Como-Sabetti K, Christianson R, Williams $D$, et al. Healthcare professional surveys: judicious antibiotic use in Minnesota long-term care facilities. J Am Geriatr Soc 2007; 55:473-4.

252. Loeb M, Bentley DW, Bradley S, Crossley K, Garibaldi R, Gantz N, et al. Development of minimum criteria for the initiation of antibiotics in residents of long-term-care facilities: results of a consensus conference. Infect Control Hosp Epidemiol 2001;22:120-4.

253. Monette J, Miller MA, Monette M, Laurier C, Boivin JF, Sourial N, et al. Effect of an educational intervention on optimizing antibiotic prescribing in long-term care facilities. J Am Geriatr Soc 2007;55:| 23 |-5.

254. Schwartz DN, Abiad H, DeMarais PL, Armeanu E, Trick WE, Wang Y, et al. An educational intervention to improve antimicrobial use in a hospital-based long-term care facility. J Am Geriatr Soc 2007;55: 1236-42.

255. Healthcare Financing Administration. Long-term care survey process training manual. Springfield, VA: National Technical Information Service; 1986.

256. Rusnak PG, Boehlem MC. Regulations, policies and procedures. In: Smith PW, editor. Infection control in long-term care facilities. 2nd ed. Albany, NY: Delmar Publishers Inc.; 1994.
257. Joint Committee on Healthcare Laundry Guidelines. Guidelines for healthcare linen service. 1999.

258. Sehulster L, Chinn RY, CDC, HICPAC. Guidelines for environmental infection control in health-care facilities: recommendations of CDC and the Healthcare Infection Control Practices Advisory Committee (HICPAC). MMWR Recomm Rep 2003;52:I-42s.

259. Linnemann CC. Nosocomial infections assocziated with physical therapy, including hydrotherapy. In: Mayhall CG, editor. Hospital epidemiology and infection control. Baltimore, MD: Williams \& Wilkins; 1996.

260. Haberstich NJ. Infection control measures: the environmental reservoir. In: Smith PW, editor. Infection control in long-term care facilities. 2nd ed. Albany, NY: Delmar Publishers, Inc.; 1994.

26I. Rutala WA. APIC guideline for selection and use of disinfectants. 1994, 1995, and 1996 APIC Guidelines Committee. Association for Professionals in Infection Control and Epidemiology, Inc. Am J Infect Control 1996;24:313-42.

262. US Department of Health and Human services, Food and Drug Administration. Guidance for FDA Staff and Industry, Section 300.500 Reprocessing of single use devices (CPG 7124.16). Available at: http://www.fda.gov/ora/compliance_ref/cpg/cpgdev/cpg300-500.html. Accessed July 2008.

263. Weatherly KS, Kenwood L, Hlusko DL, Franklin KG. Product evaluation process: a systems approach to controlling health care costs. AORN J 1994;59:489-98.

264. Rutala WA, Mayhall CG. Medical waste. Infect Control Hosp Epidemiol 1992; 13:38-48.

265. Environmental Protection Agency. Standards for the tracking and management of medical waste. Fed Regist 1989;54:I2326-95.

266. Centers for Medicare and Medicaid Services (CMS). Chapter 3: item-by-item guide to the MDS. , Long-term care facility resident assessment instrument user's manual. Washington, DC: CMS; 2002.

267. Stevenson KB, Moore JW, Sleeper B. Validity of the minimum data set in identifying urinary tract infections in residents of long-term care facilities. J Am Geriatr Soc 2004;52:707-II.

268. Crede W, Hierholzer WJ Jr. Linking hospital epidemiology and quality assurance: seasoned concepts in a new role. Infect Control 1988;9:42-4.

269. Stevenson KB, Loeb M. Performance improvement in the long-termcare setting: building on the foundation of infection control. Infect Control Hosp Epidemiol 2004;25:72-9.

270. Simmons BP, Kritchevsky SB. Epidemiologic approaches to quality assessment. Infect Control Hosp Epidemiol 1995; 16:101-4.

27I. Gross PA, Barrett T, Dellinger EP, Krause PJ, Martone WJ, McGowan JE Jr, et al. Consensus development of quality standards. Infect Control Hosp Epidemiol 1994; I5: I80-I.

272. Centers for Medicare and Medicaid Services (CMS). Section W. Long-term care facility resident assessment instrument user's manual. Washington, DC: CMS; 2002.

273. Sand KL, Lynn J, Bardenheier B, Seow H, Nace DA. Increasing influenza immunization for long-term care facility staff using quality improvement. J Am Geriatr Soc 2007;55:174I-7.

274. Bellelli G, Frisoni GB, Barbisoni P, Boffelli S, Rozzini R, Trabucchi M. The management of adverse clinical events in nursing homes: a I-year survey study. J Am Geriatr Soc 200I;49:9I5-25.

275. Mody L, Cinti S. Pandemic influenza planning in nursing homes: are we prepared? J Am Geriatr Soc 2007;55:|43|-7.

276. US Department of Health and Human services, Centers for Disease Control and Prevention (CDC). Long-term care and other residential facilities pandemic influenza planning checklist. Available at: http: //www.pandemicflu.gov/plan/healthcare/longtermcarechecklist.html. Accessed July 2008.

277. Smith PW, Shostrom V, Smith A, Kaufmann M, Mody L. Preparedness for pandemic influenze in nursing homes: A 2-state survey. JAMA 2008;300:392-4. 